\title{
One-Pot Generation of Functionalized Benzynes from Readily Available 2-Hydroxyphenylboronic Acids
}

\author{
Takashi Ikawa,* JingKai Sun, Akira Takagi, Shuji Akai* \\ Graduate School of Pharmaceutical Sciences, Osaka University, Yamadaoka, Suita, \\ Osaka 565-0871, Japan. \\ Kobe Pharmaceutical University, Motoyamakita, Higashinada, Kobe 658-8558, Japan \\ E-mail: ikawa@phs.osaka-u.ac.jp, akai@phs.osaka-u.ac.jp
}

Table of contents

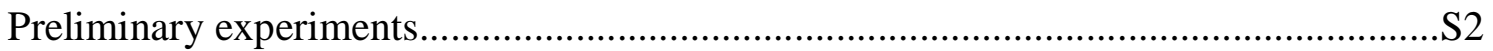

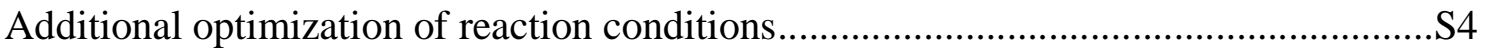

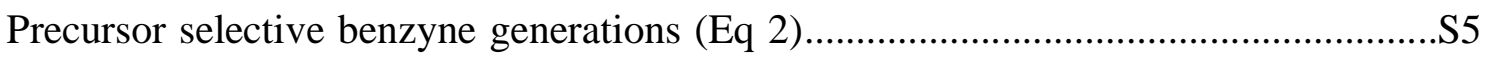

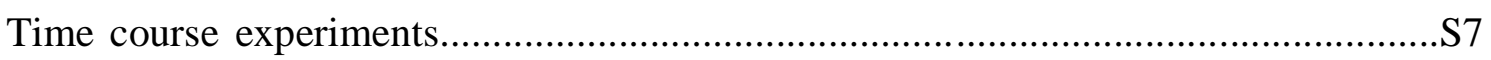

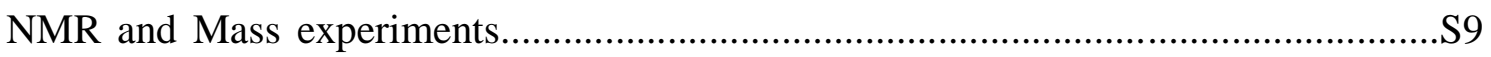

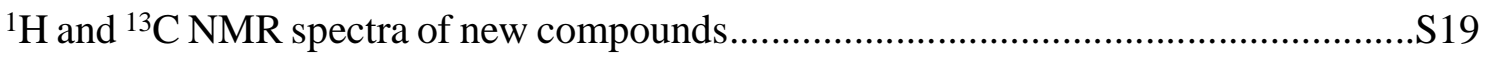




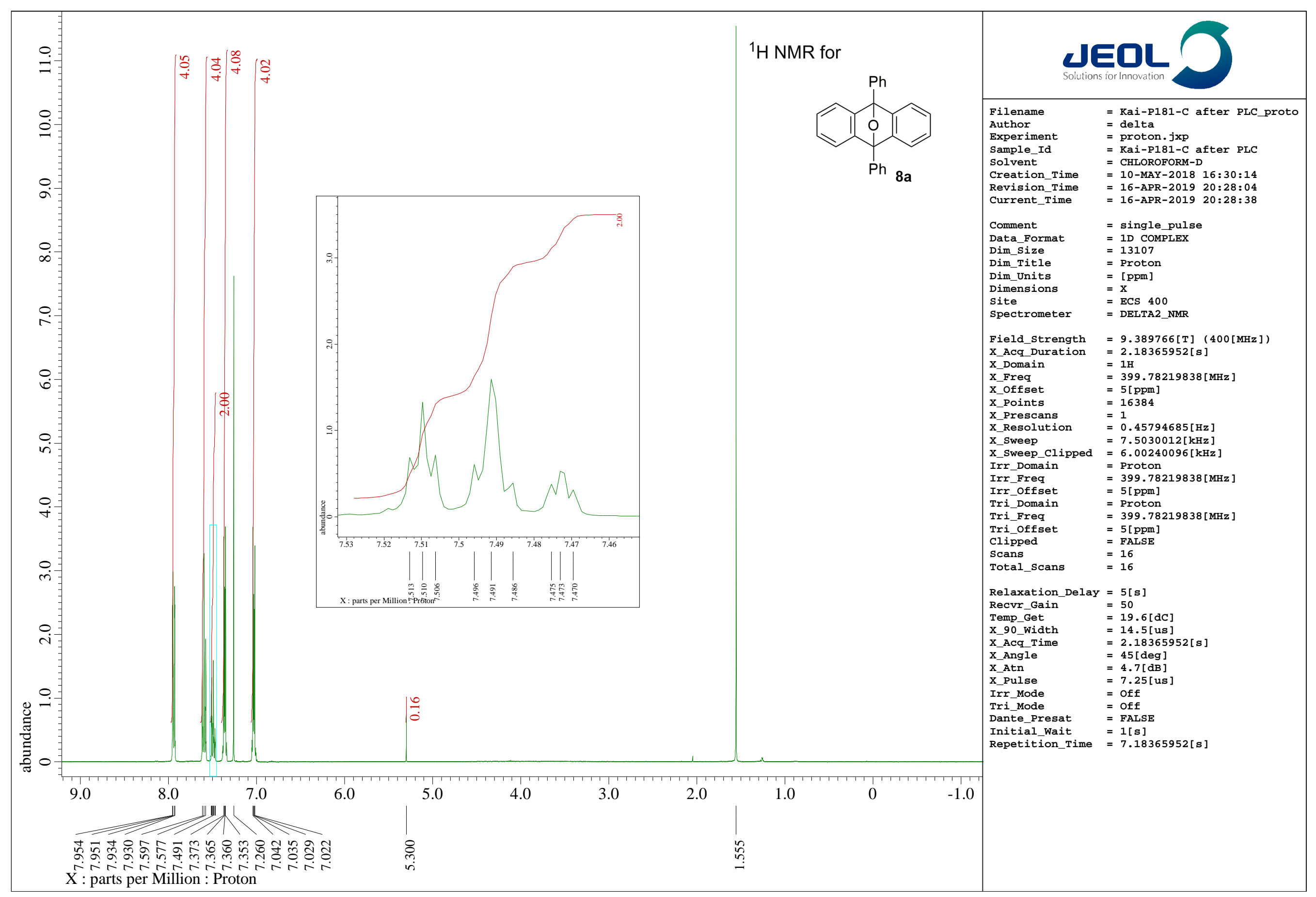




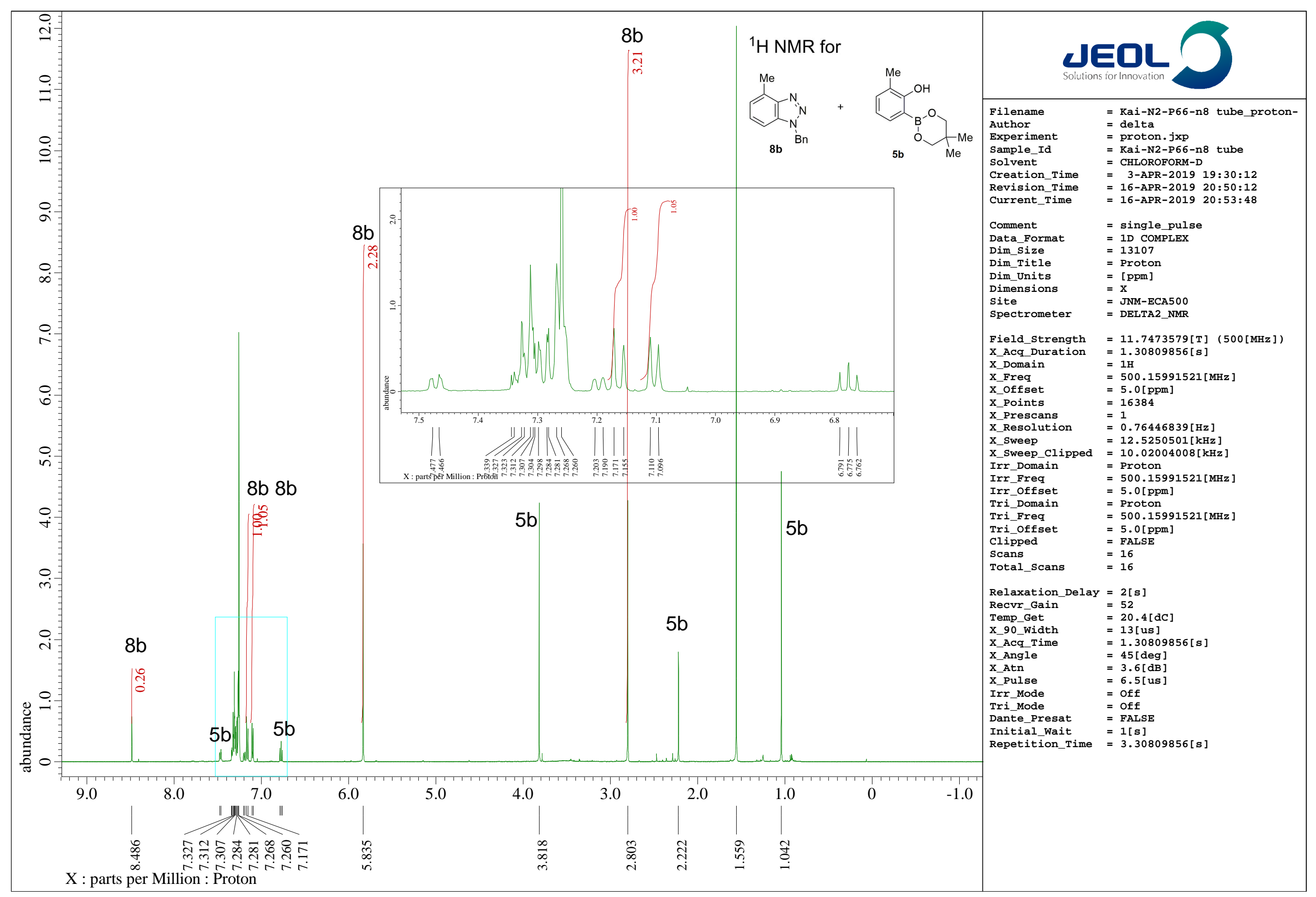




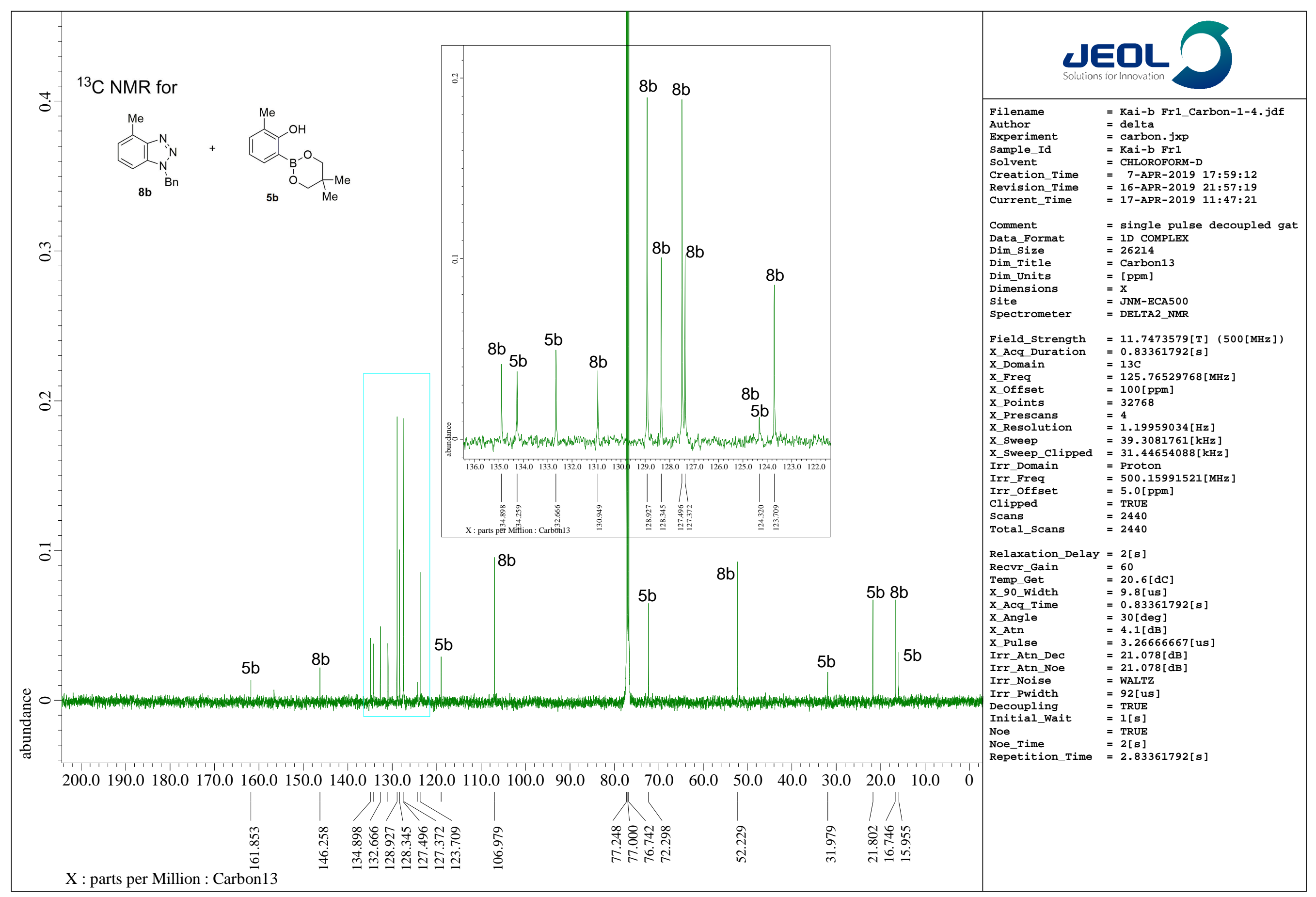




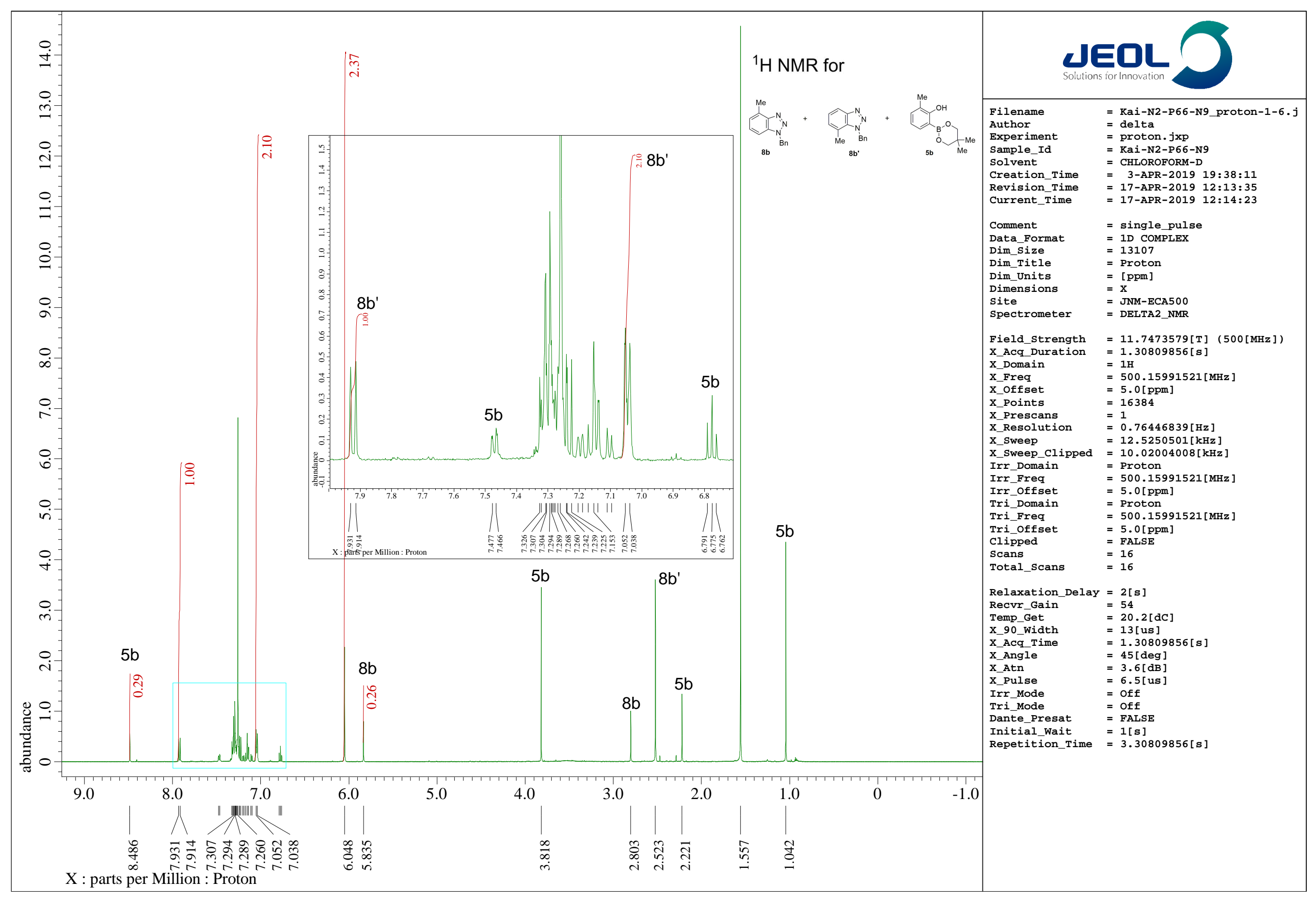




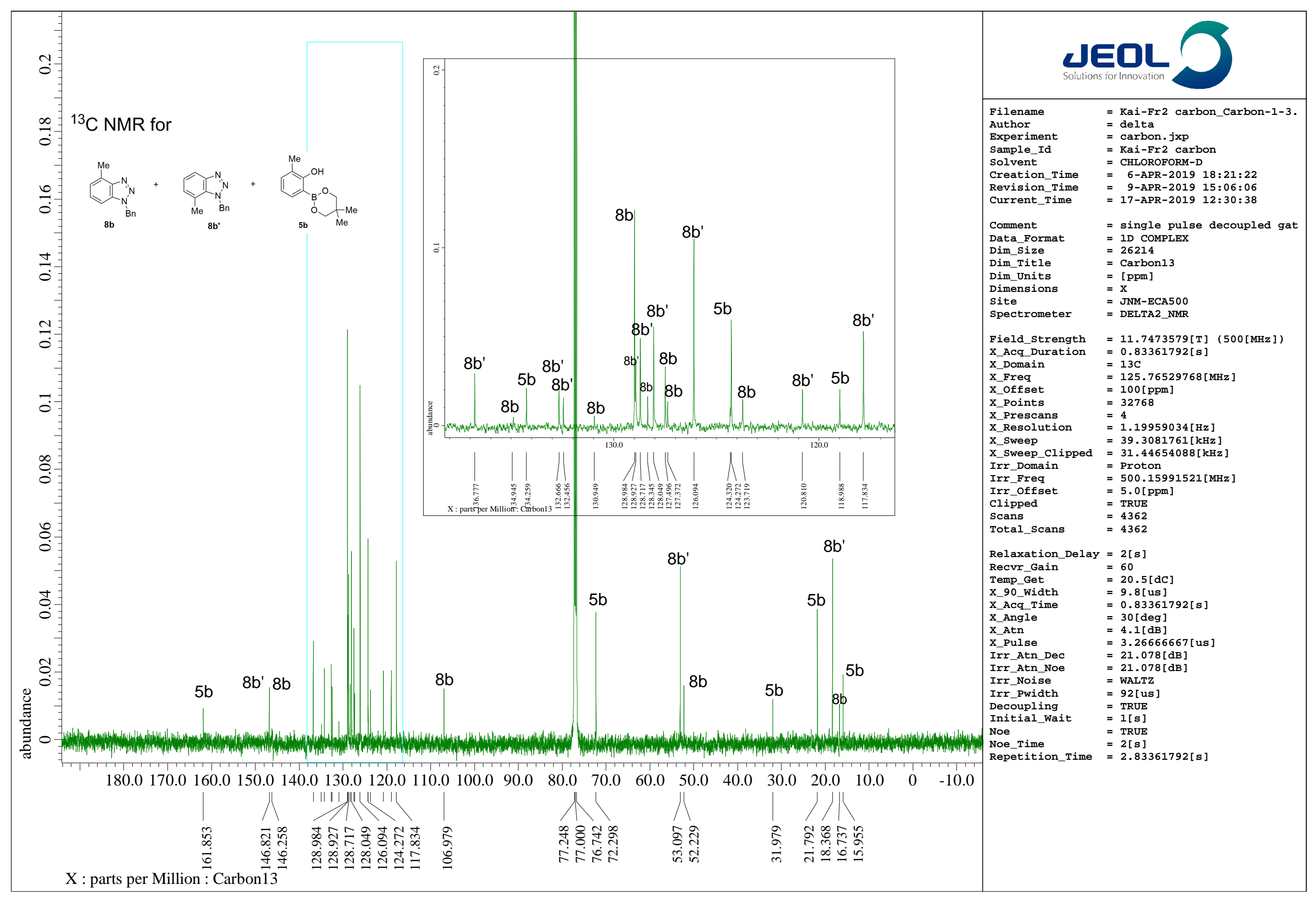




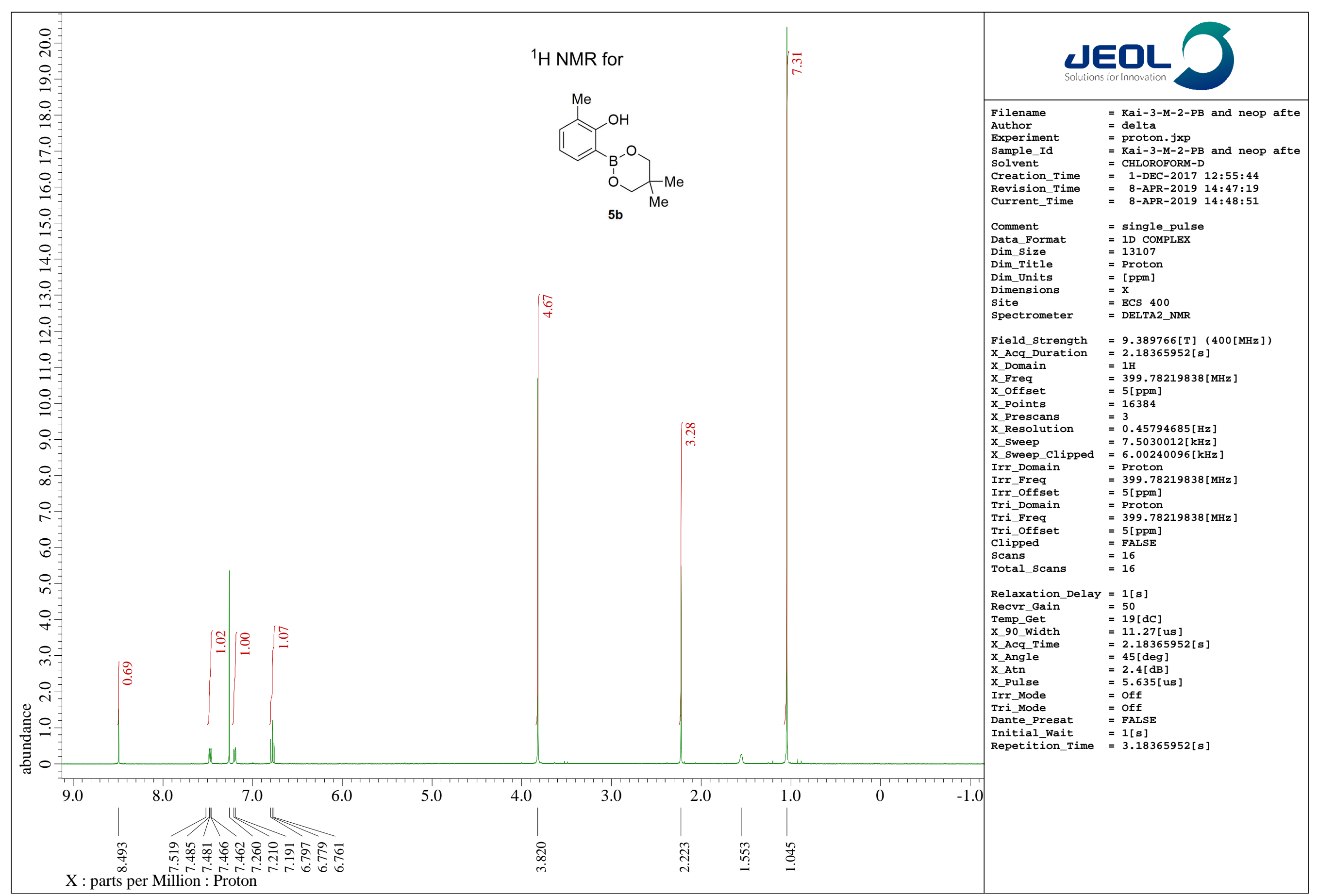




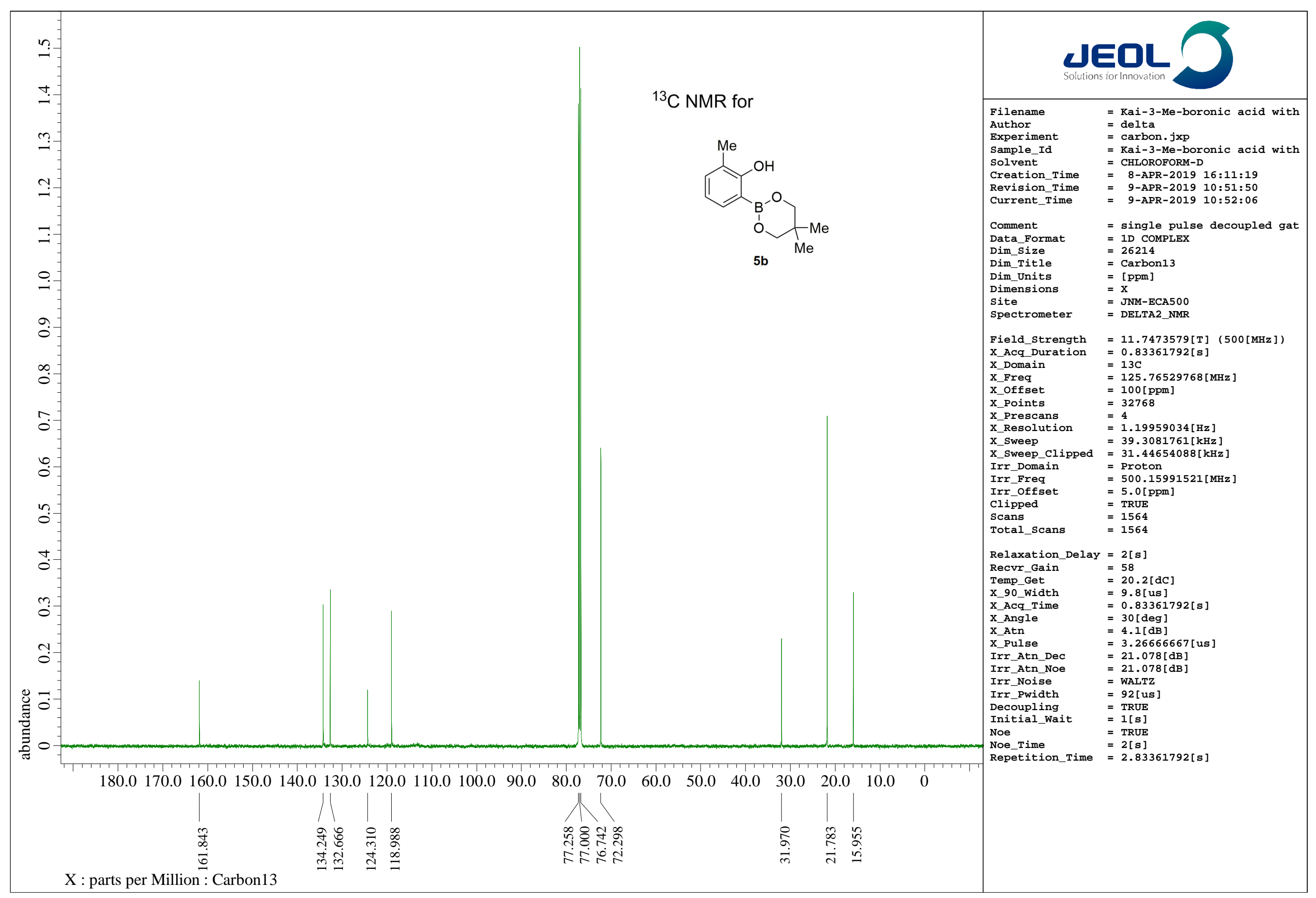




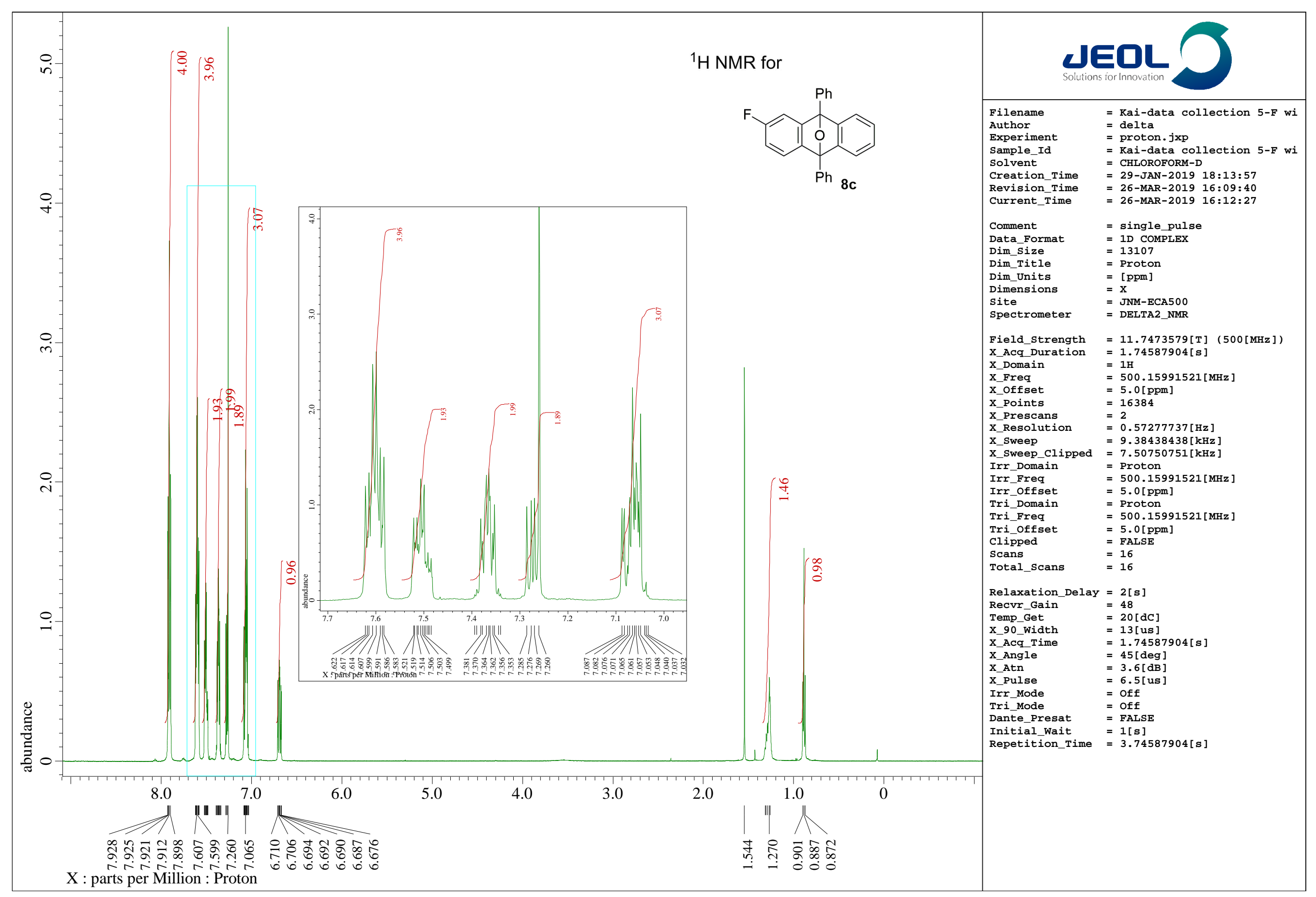




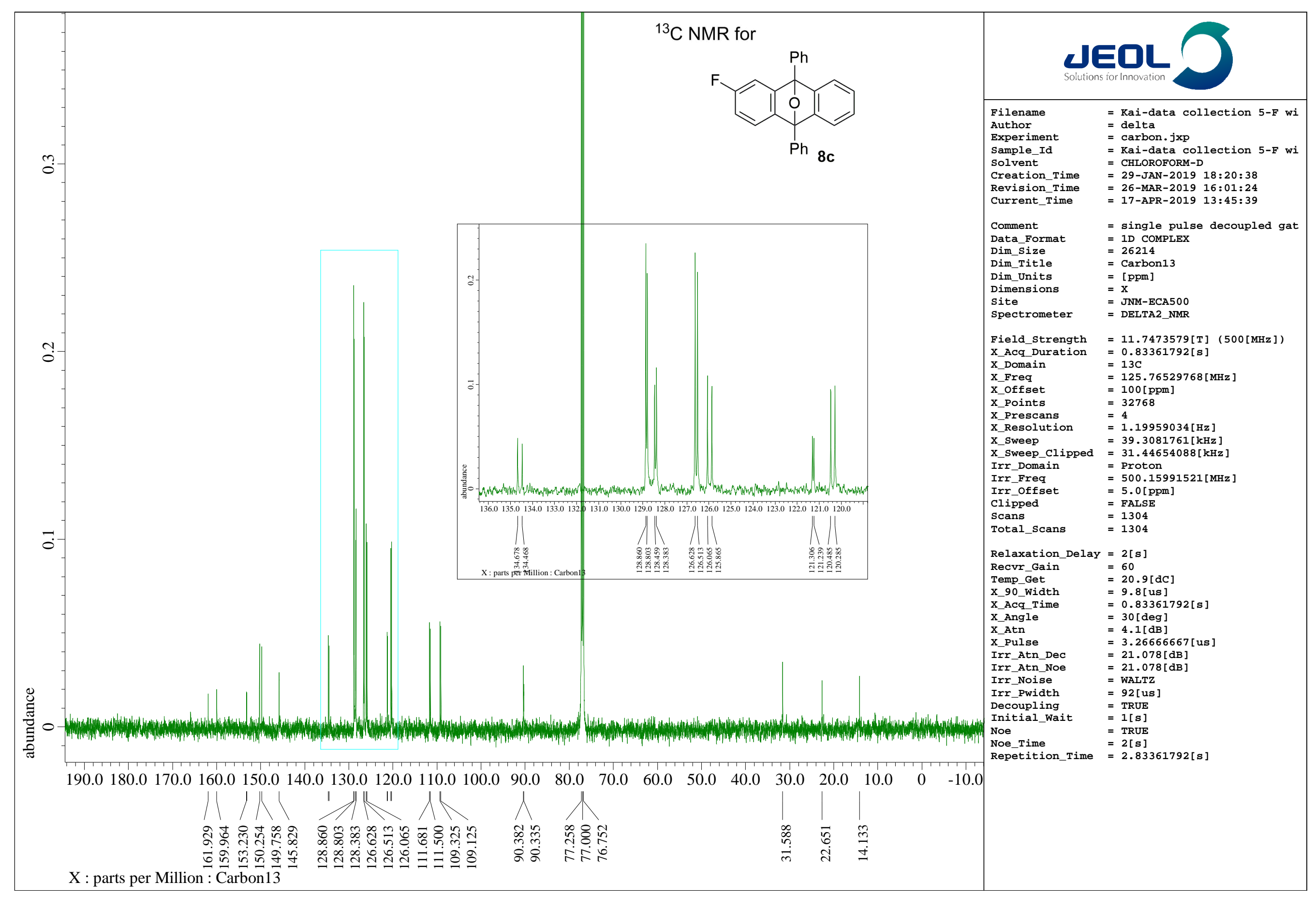




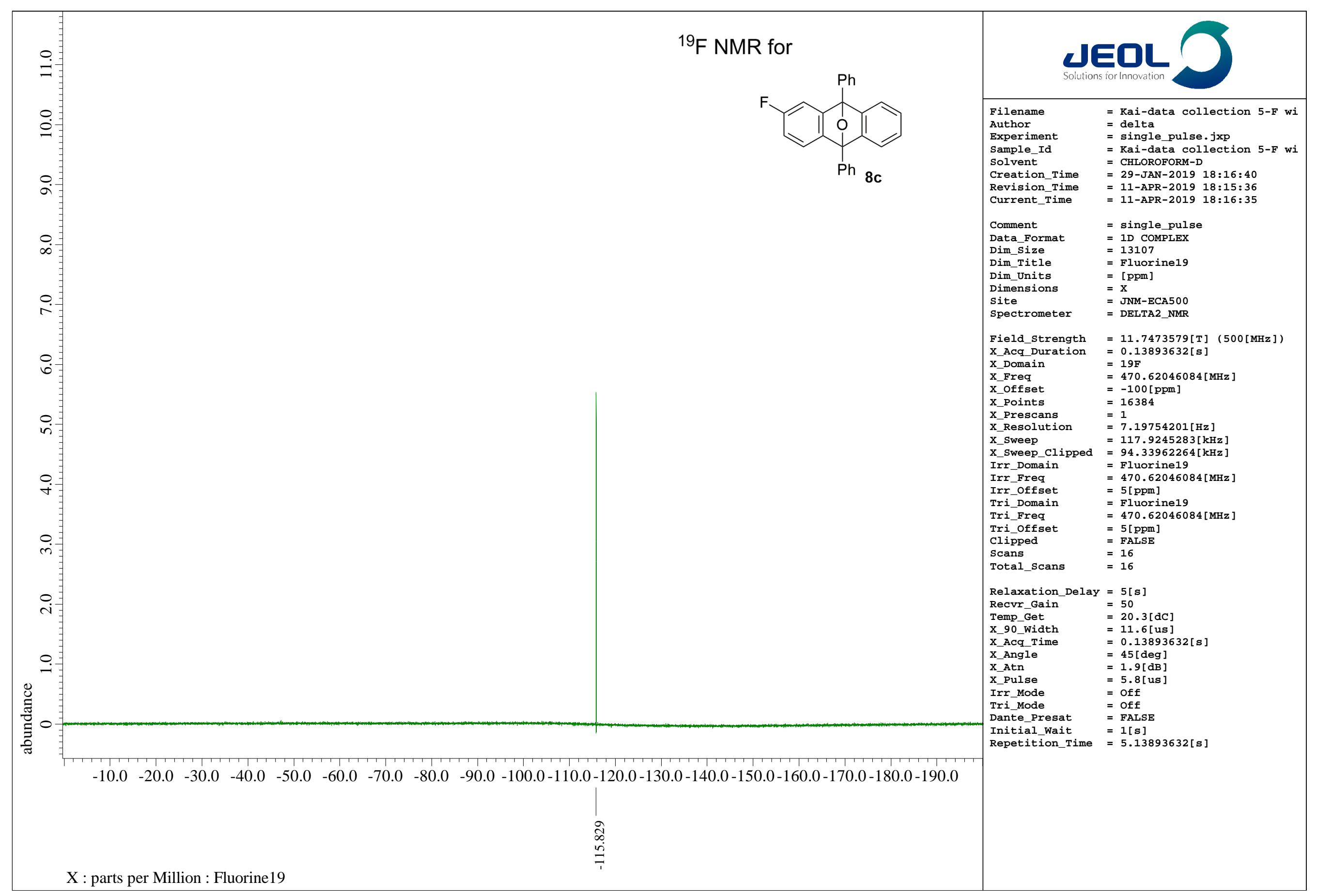




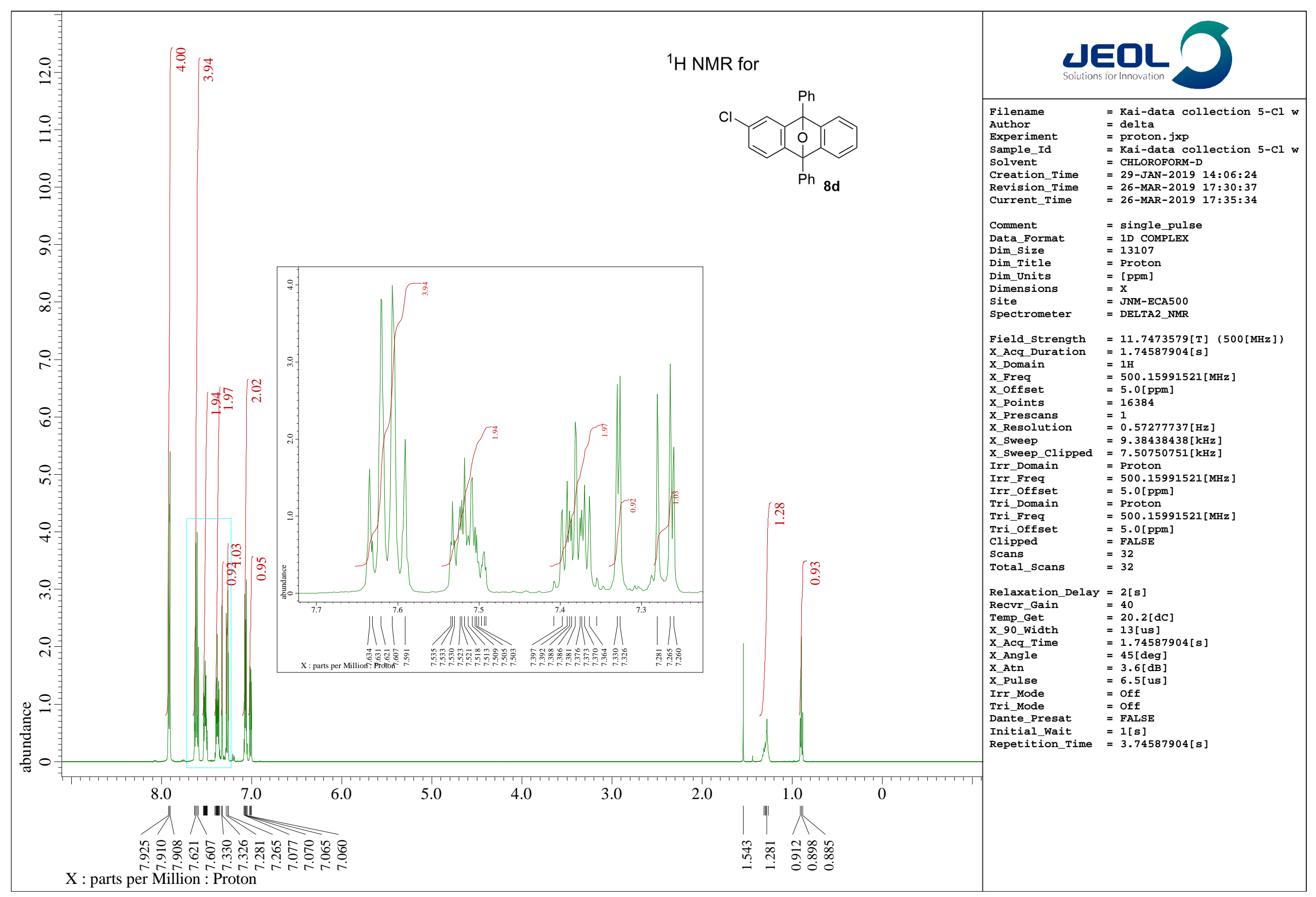




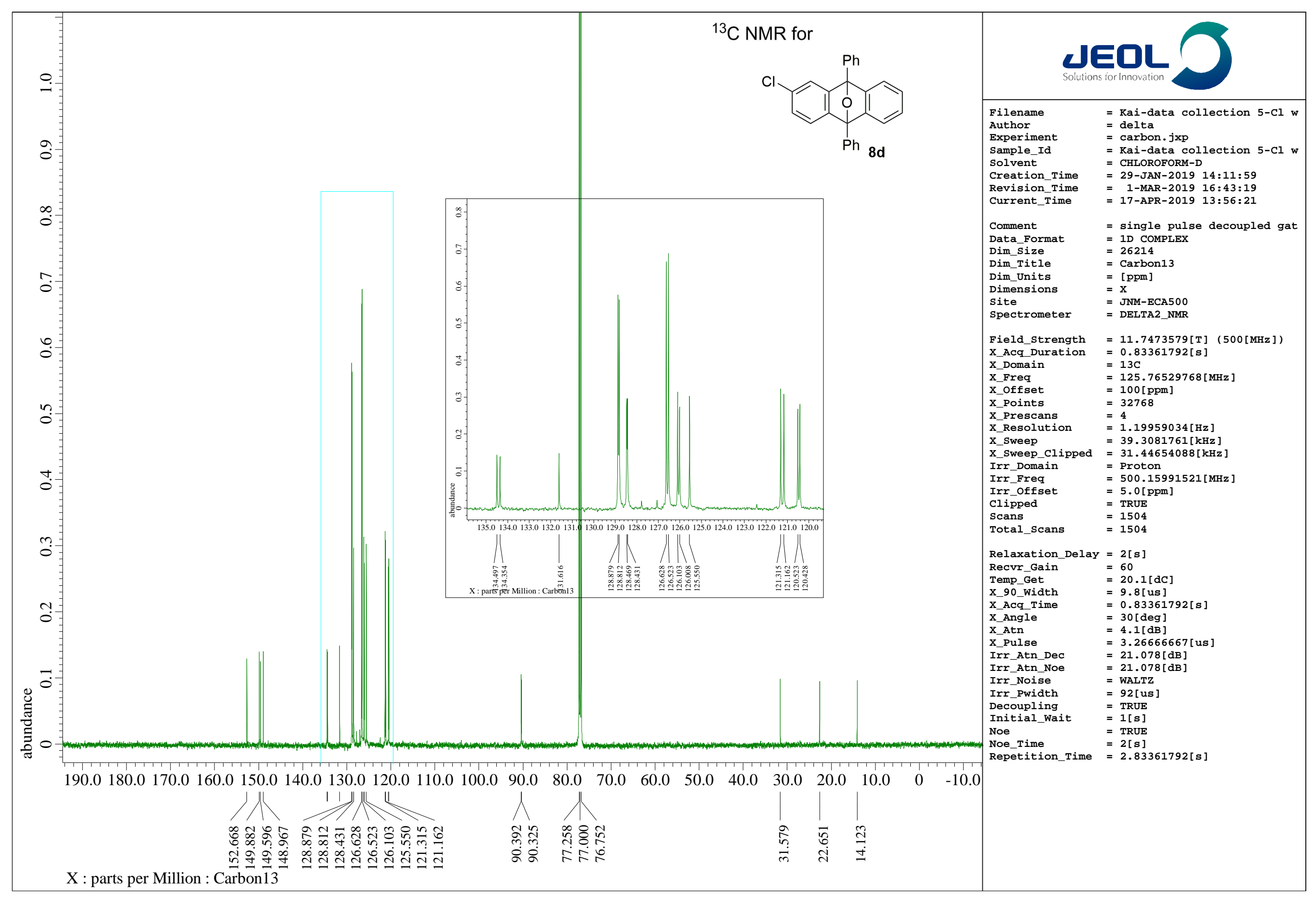




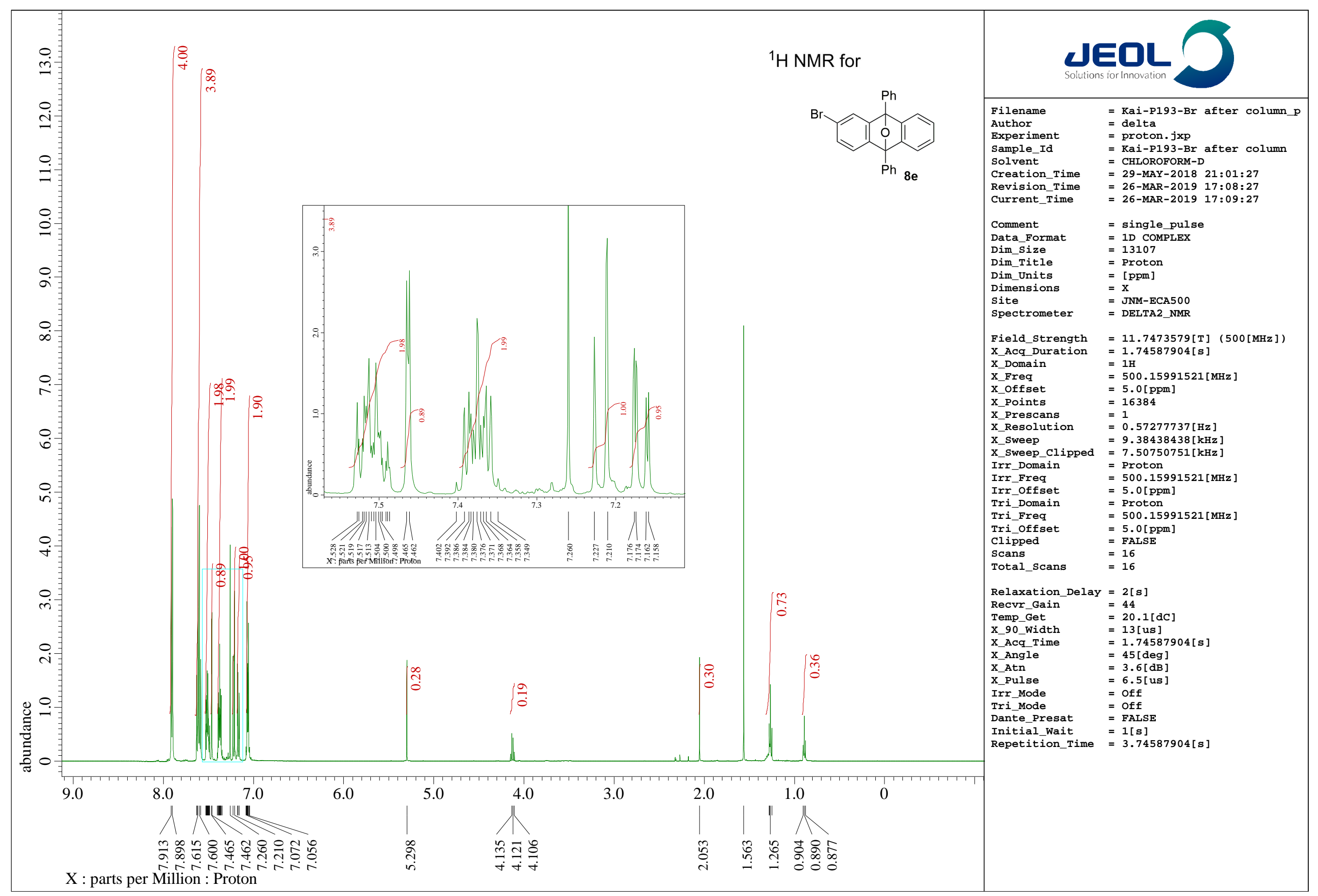




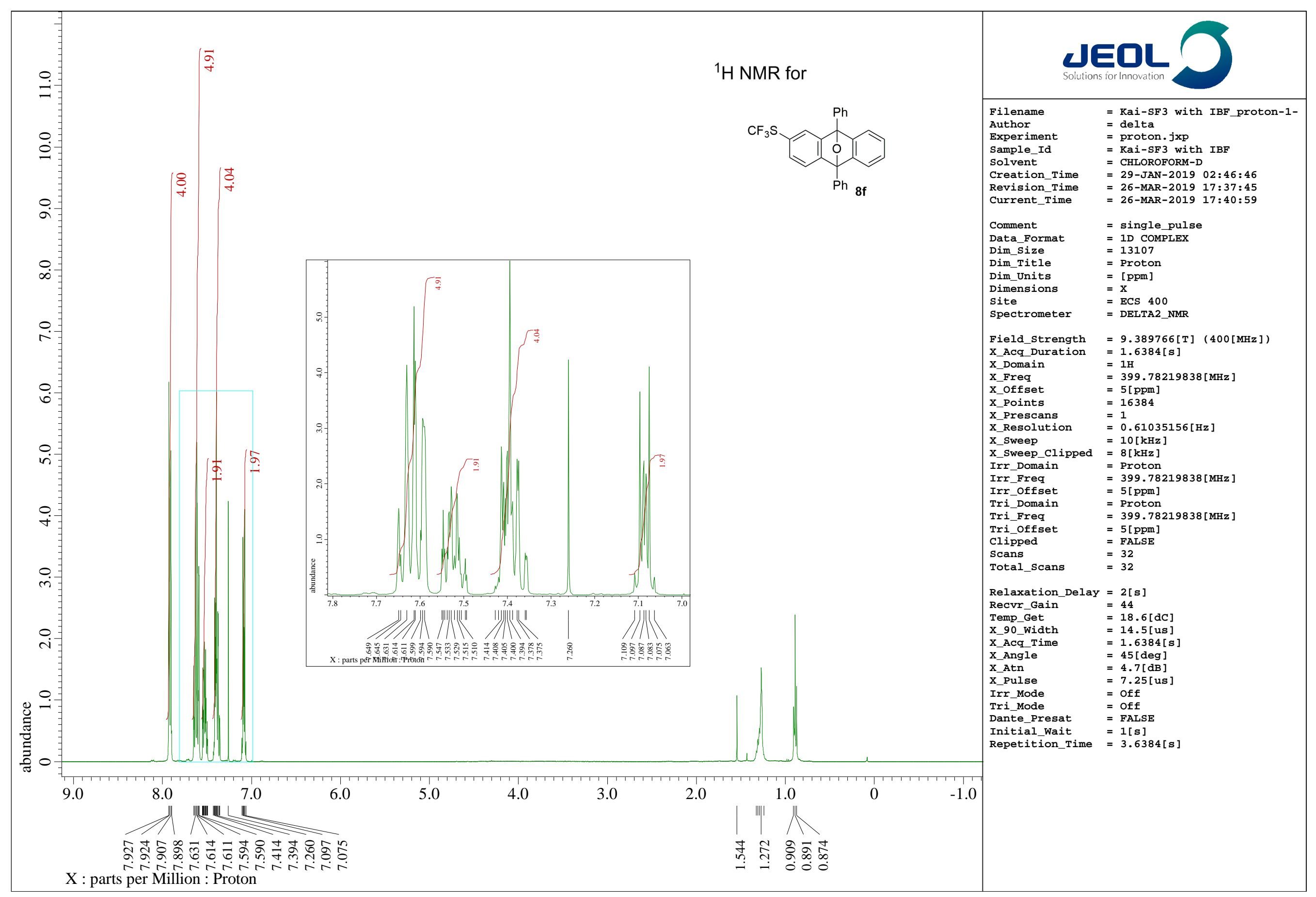




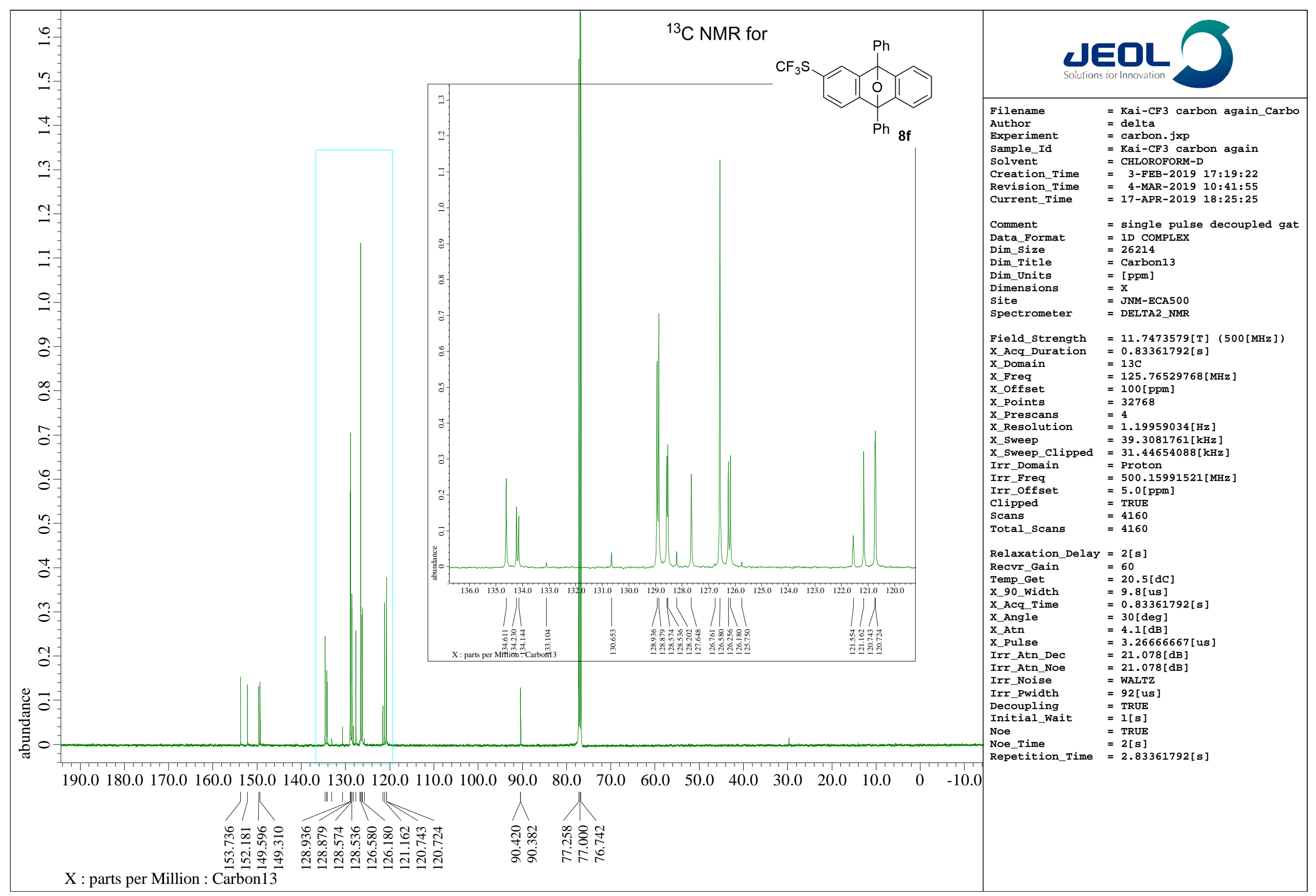




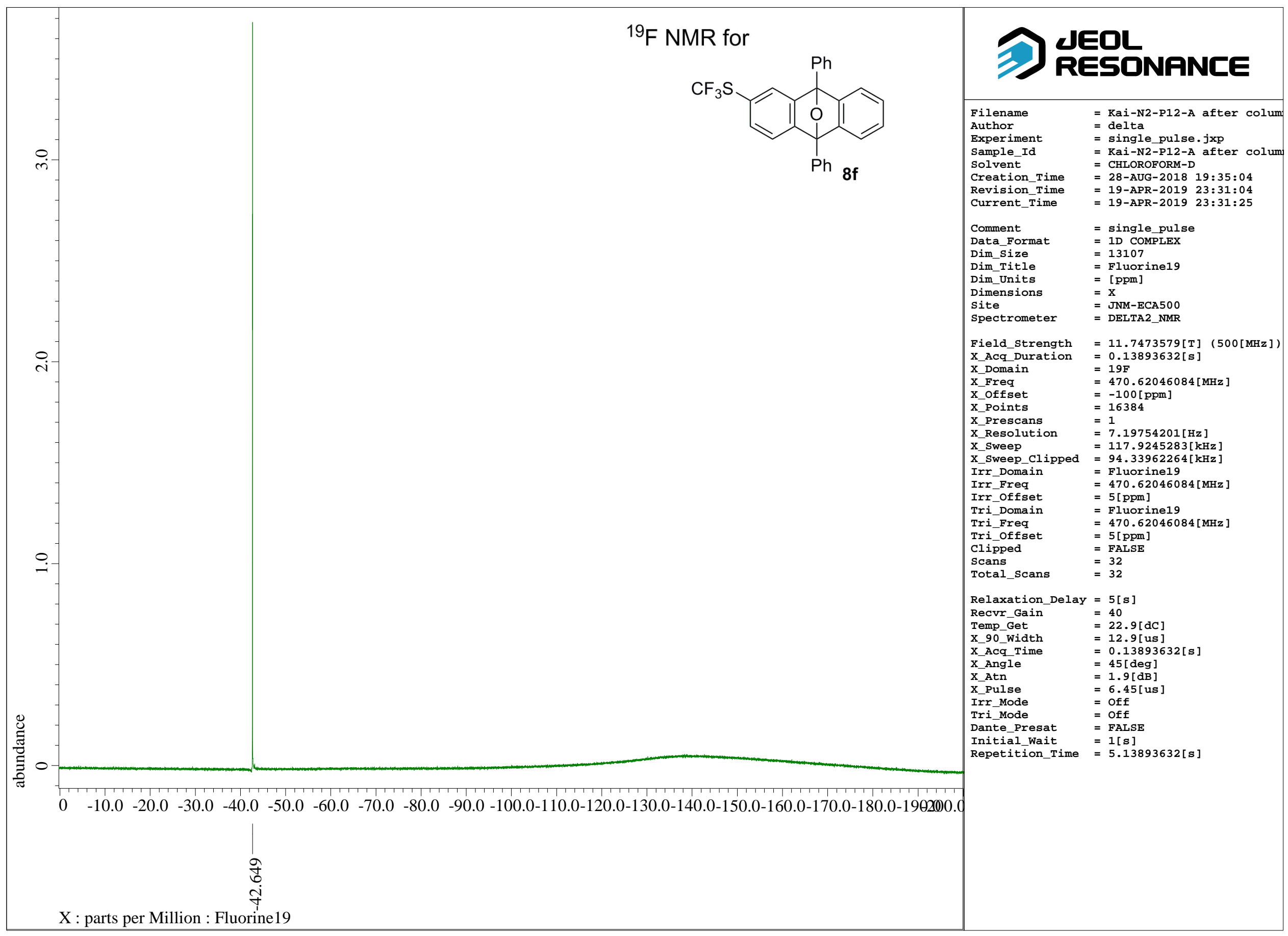




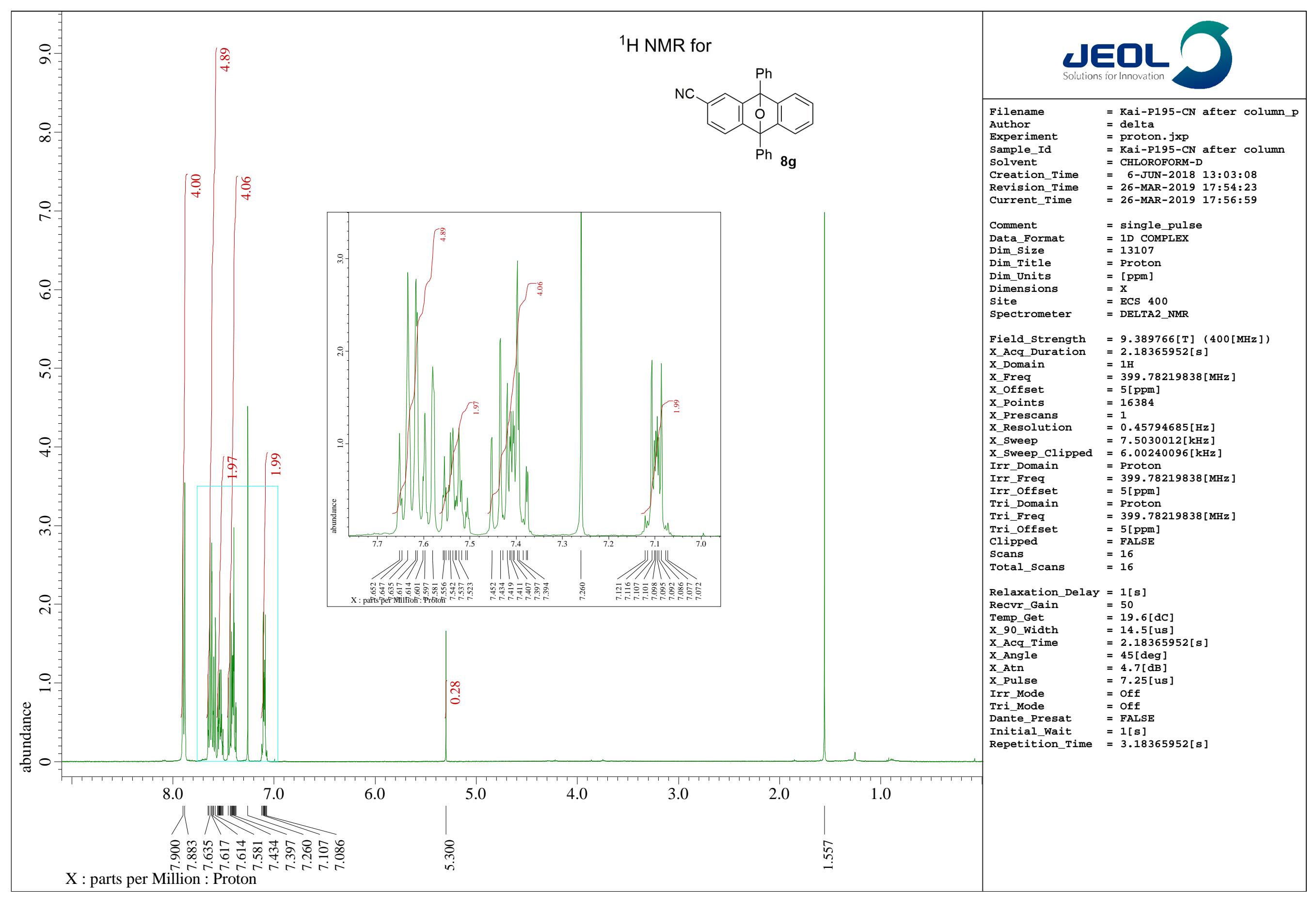




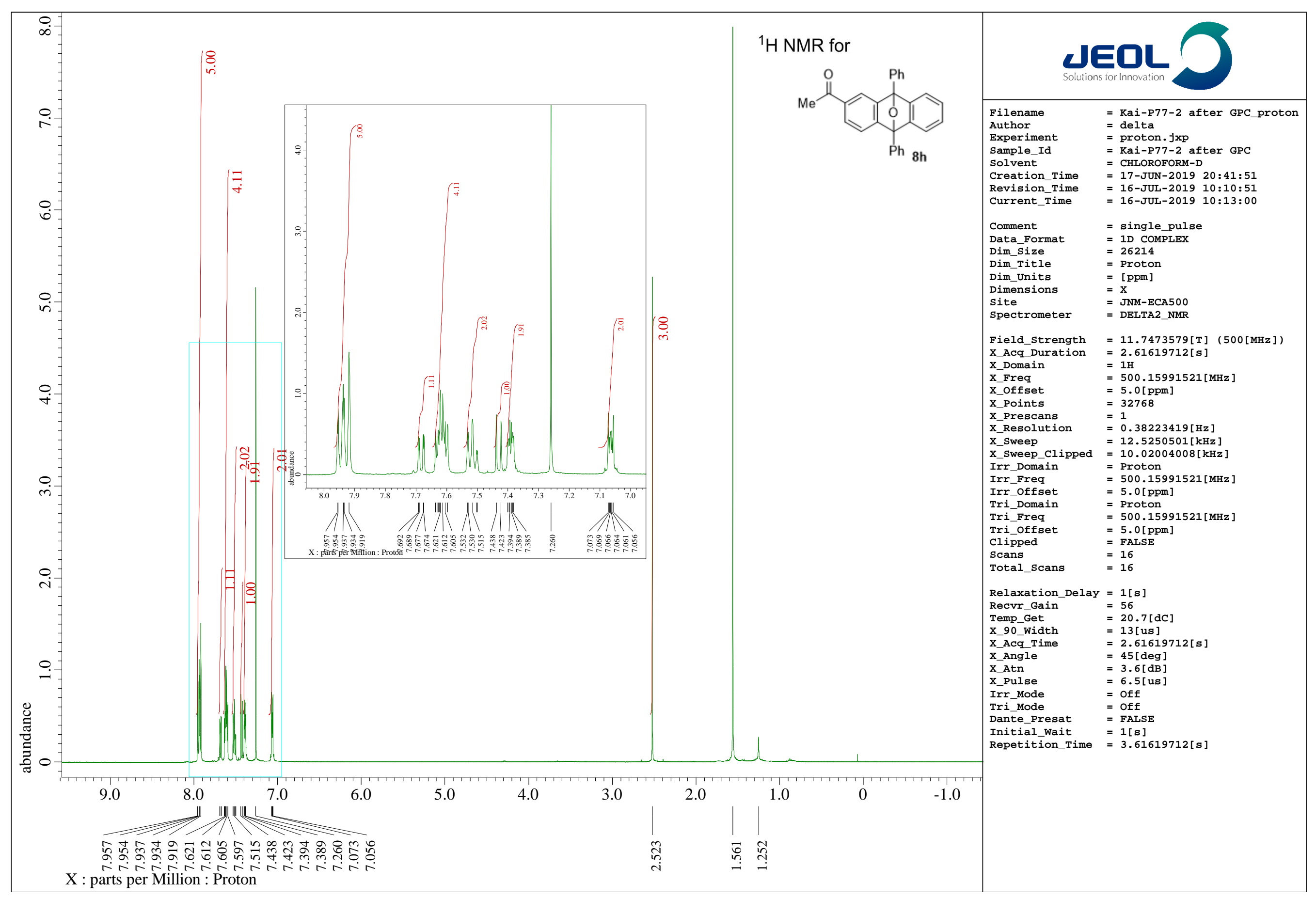




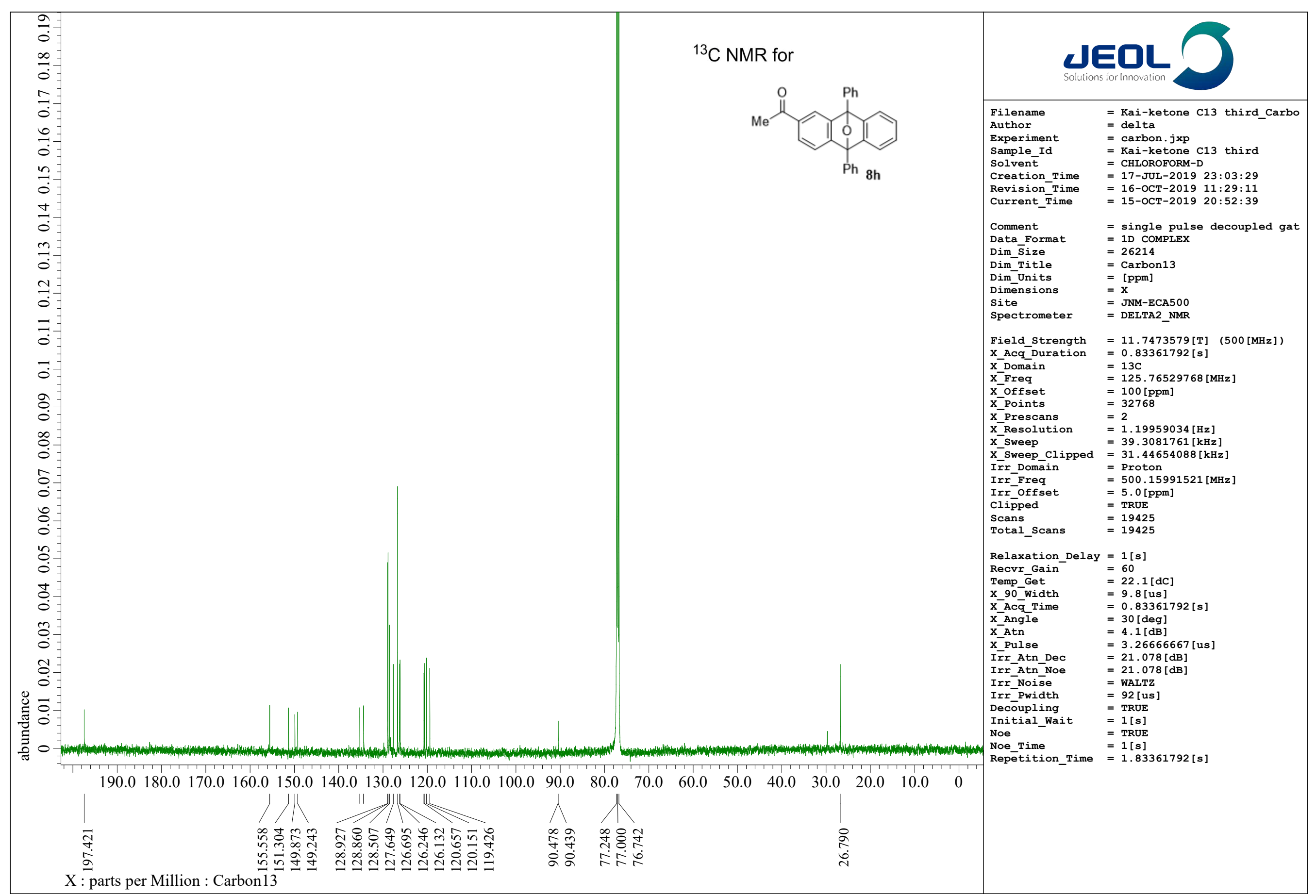




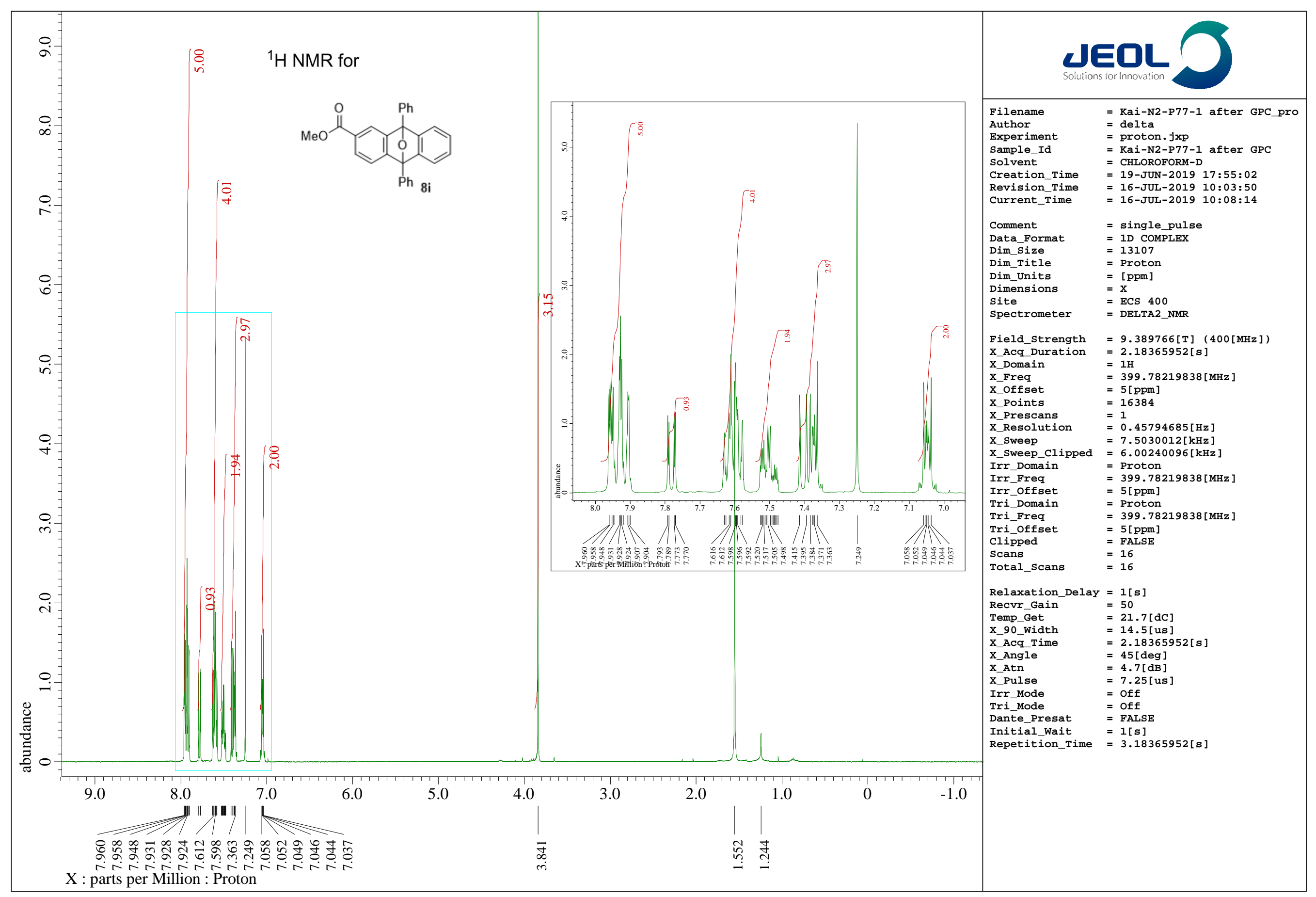




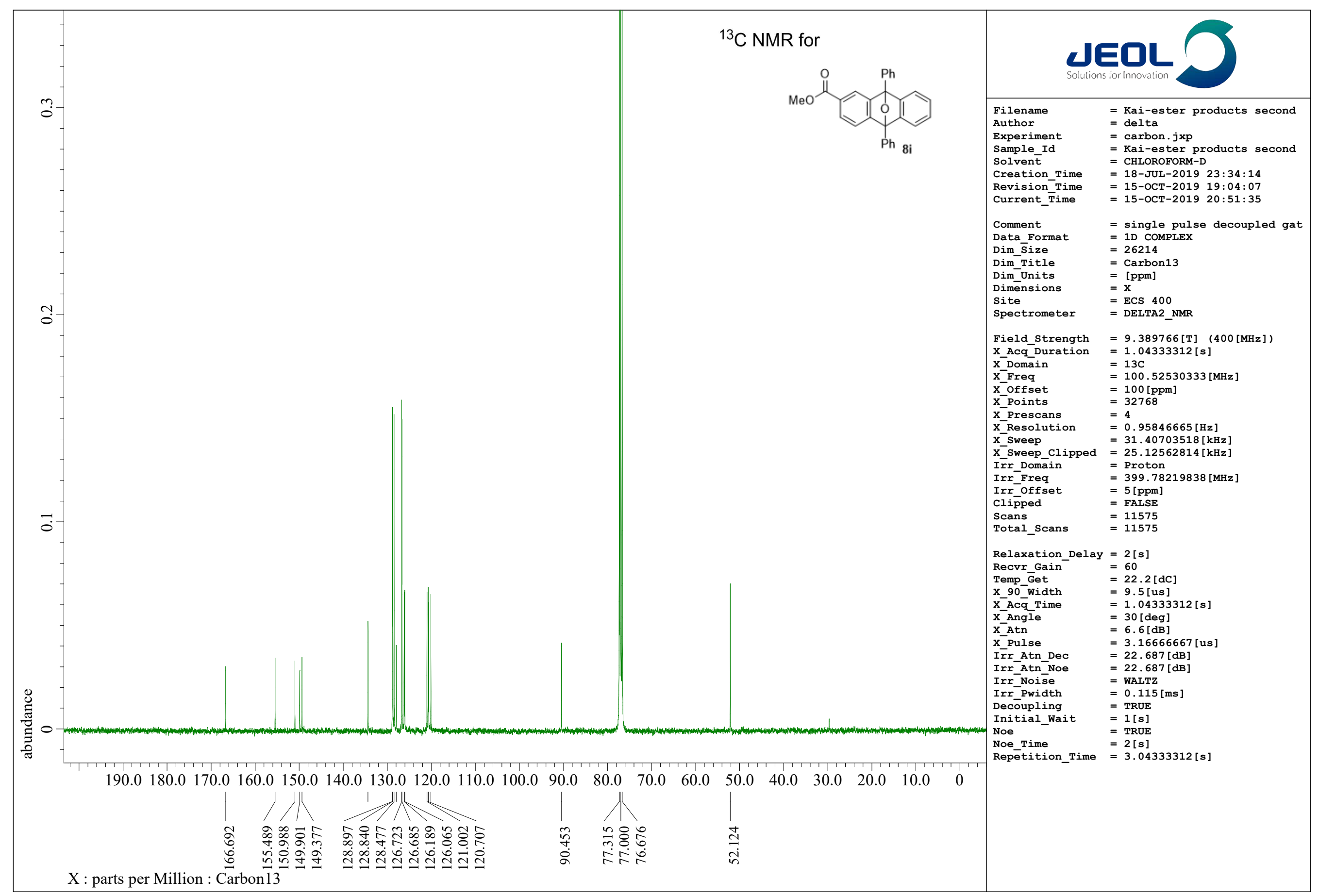




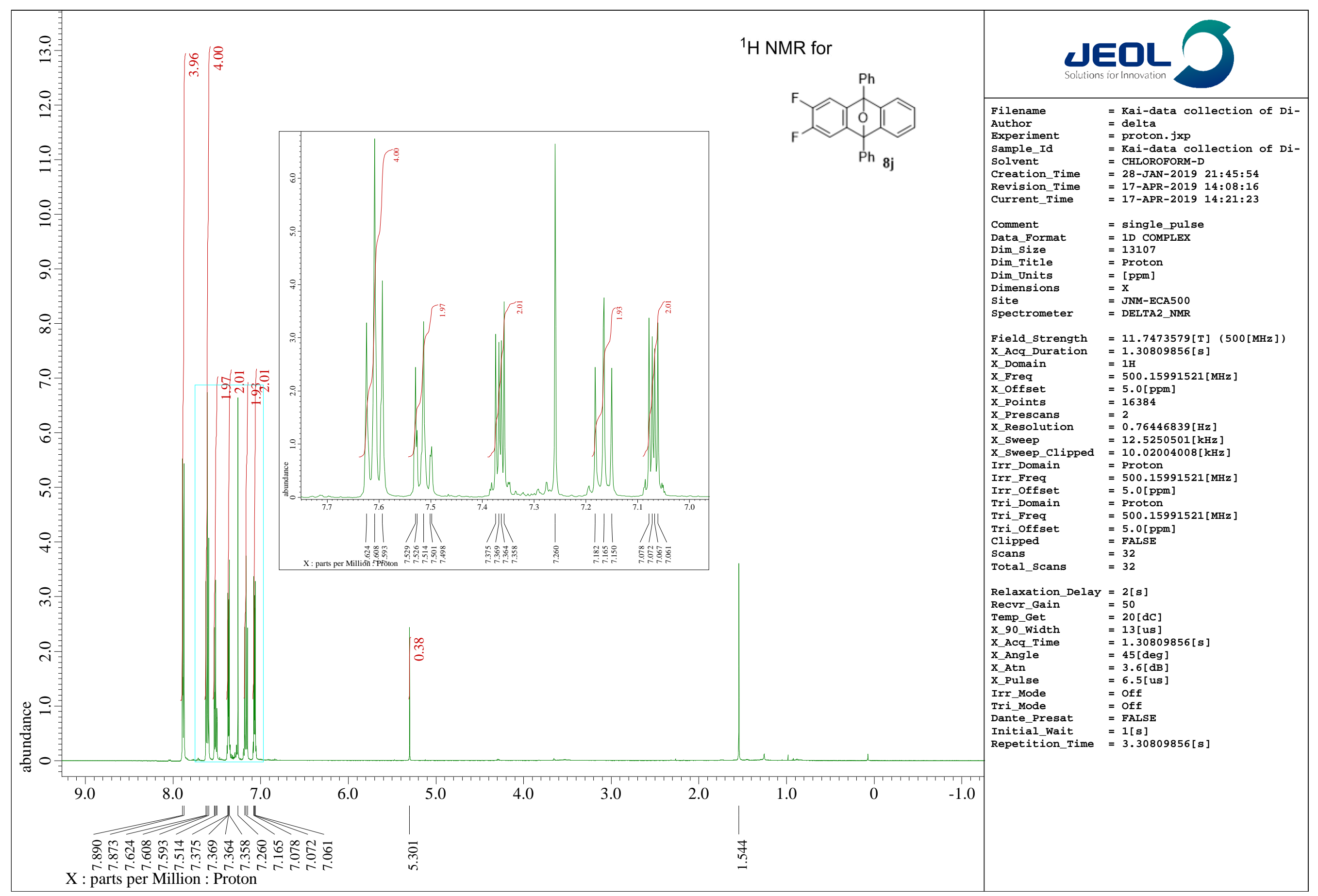




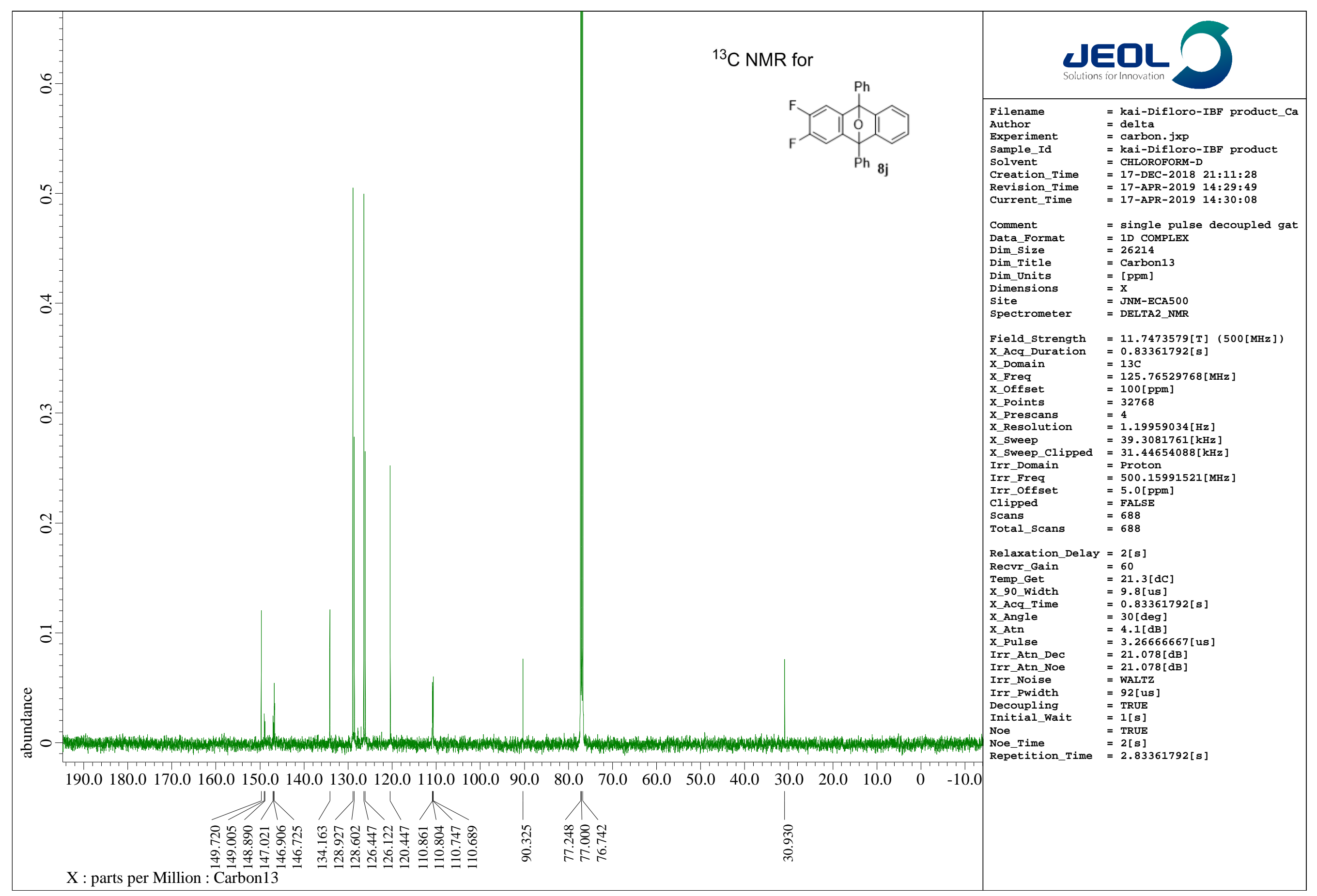




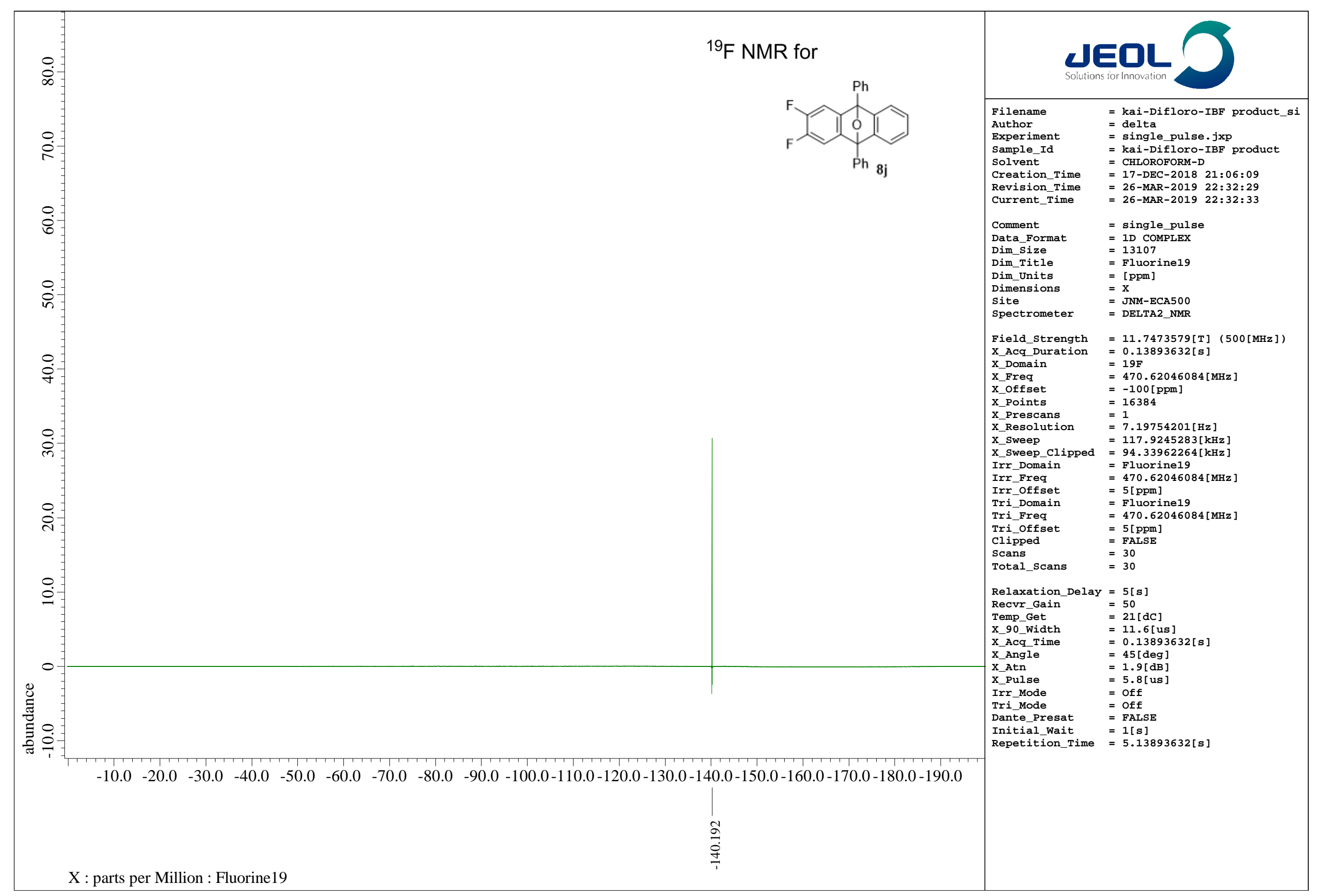




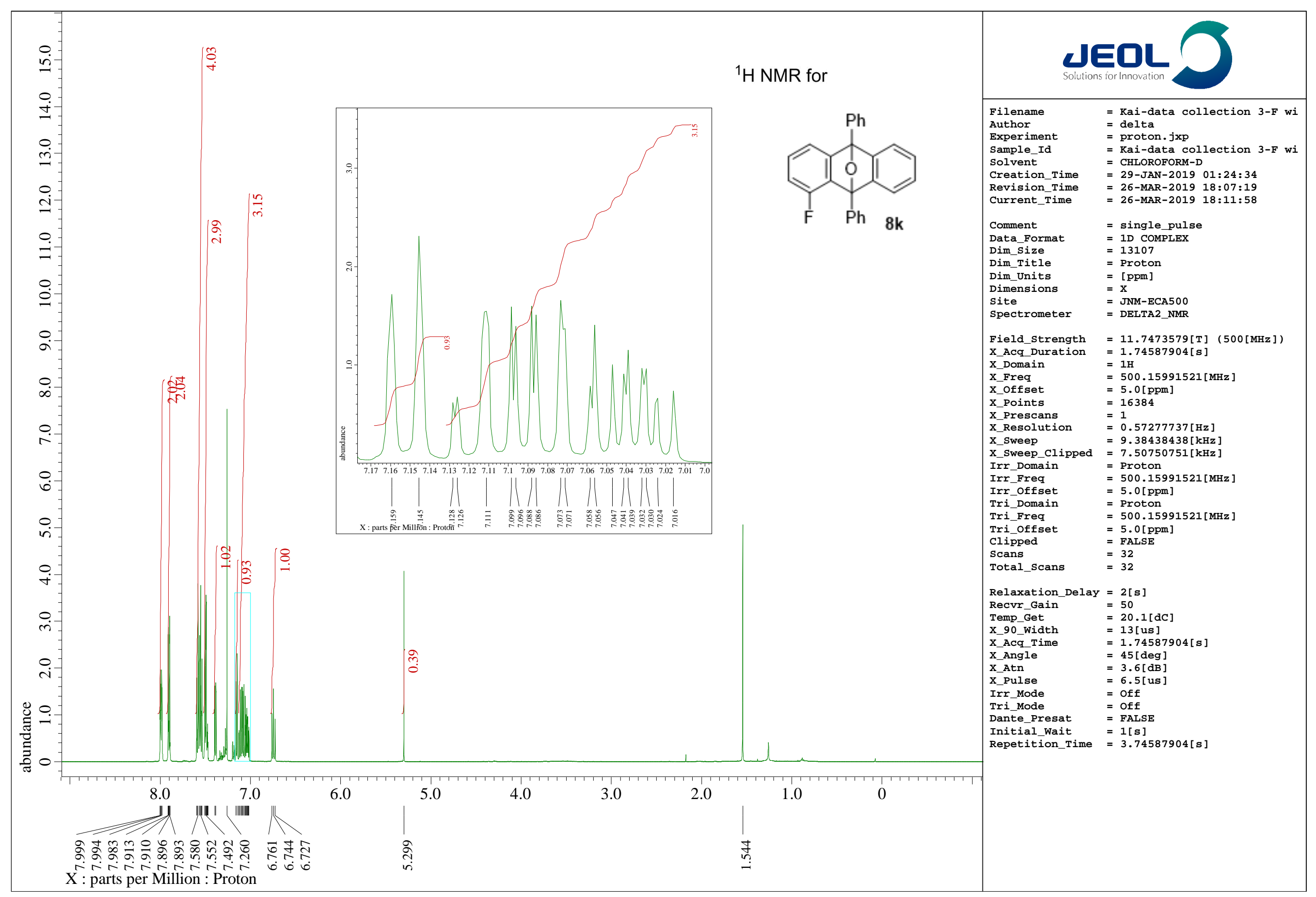




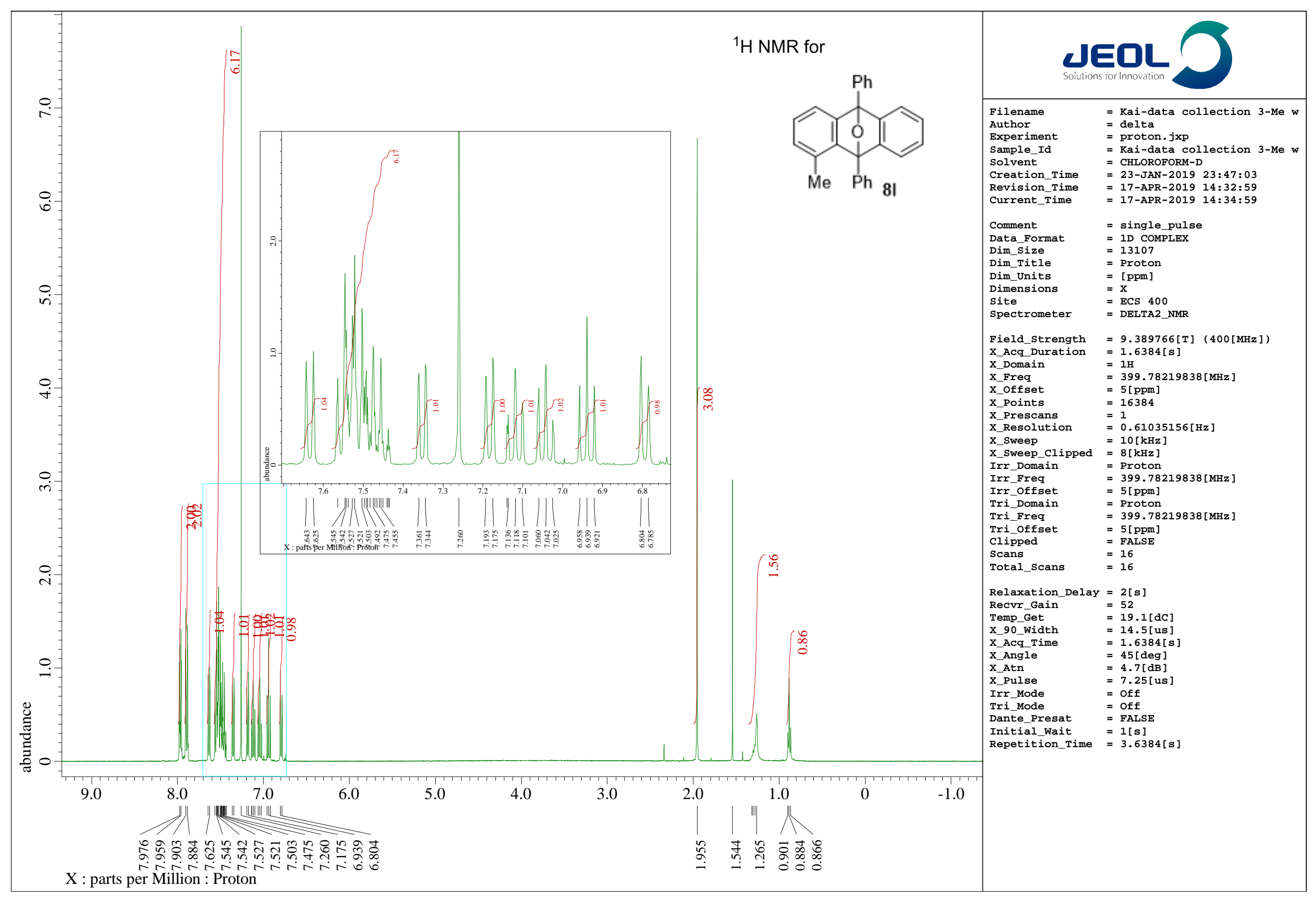




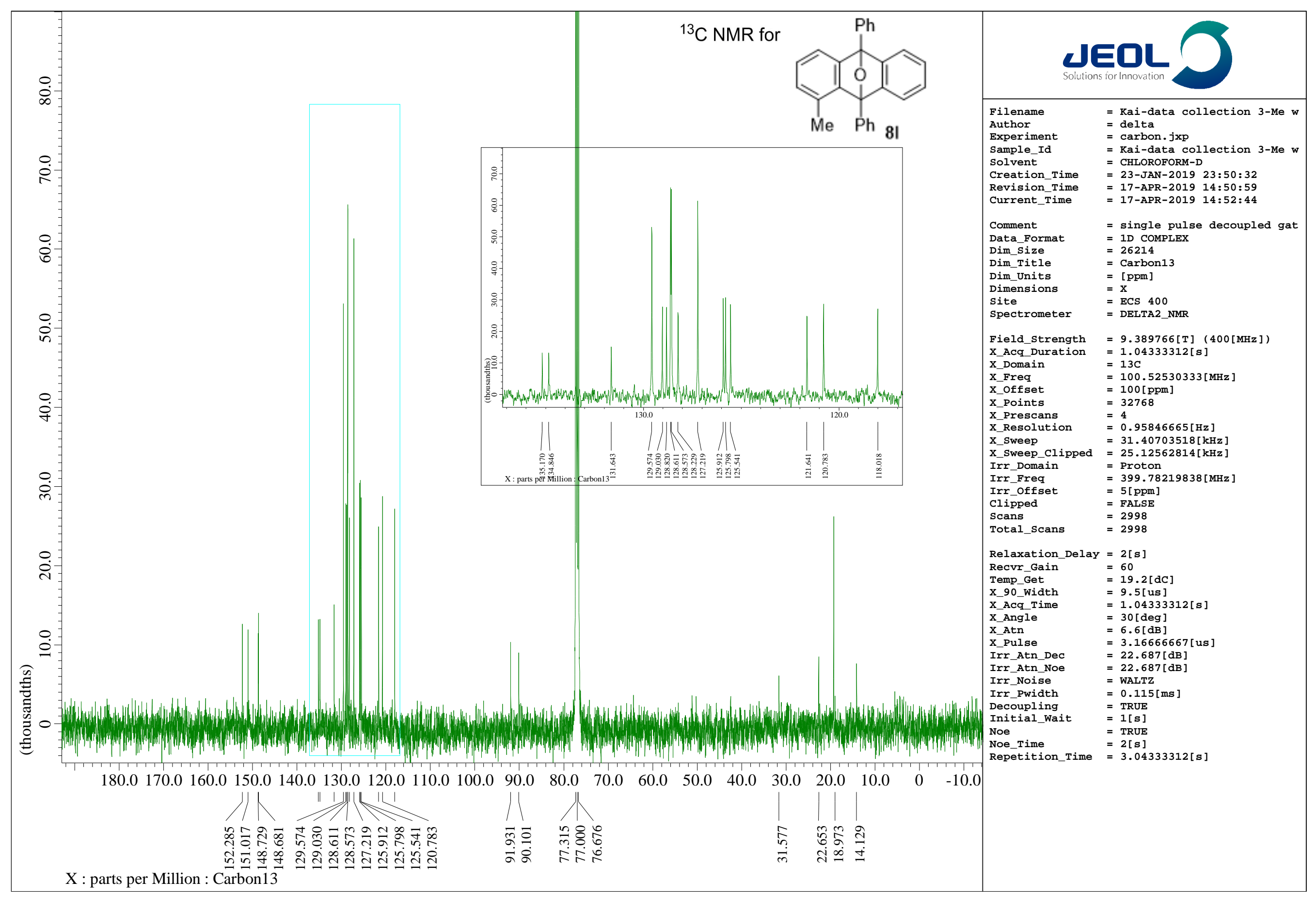




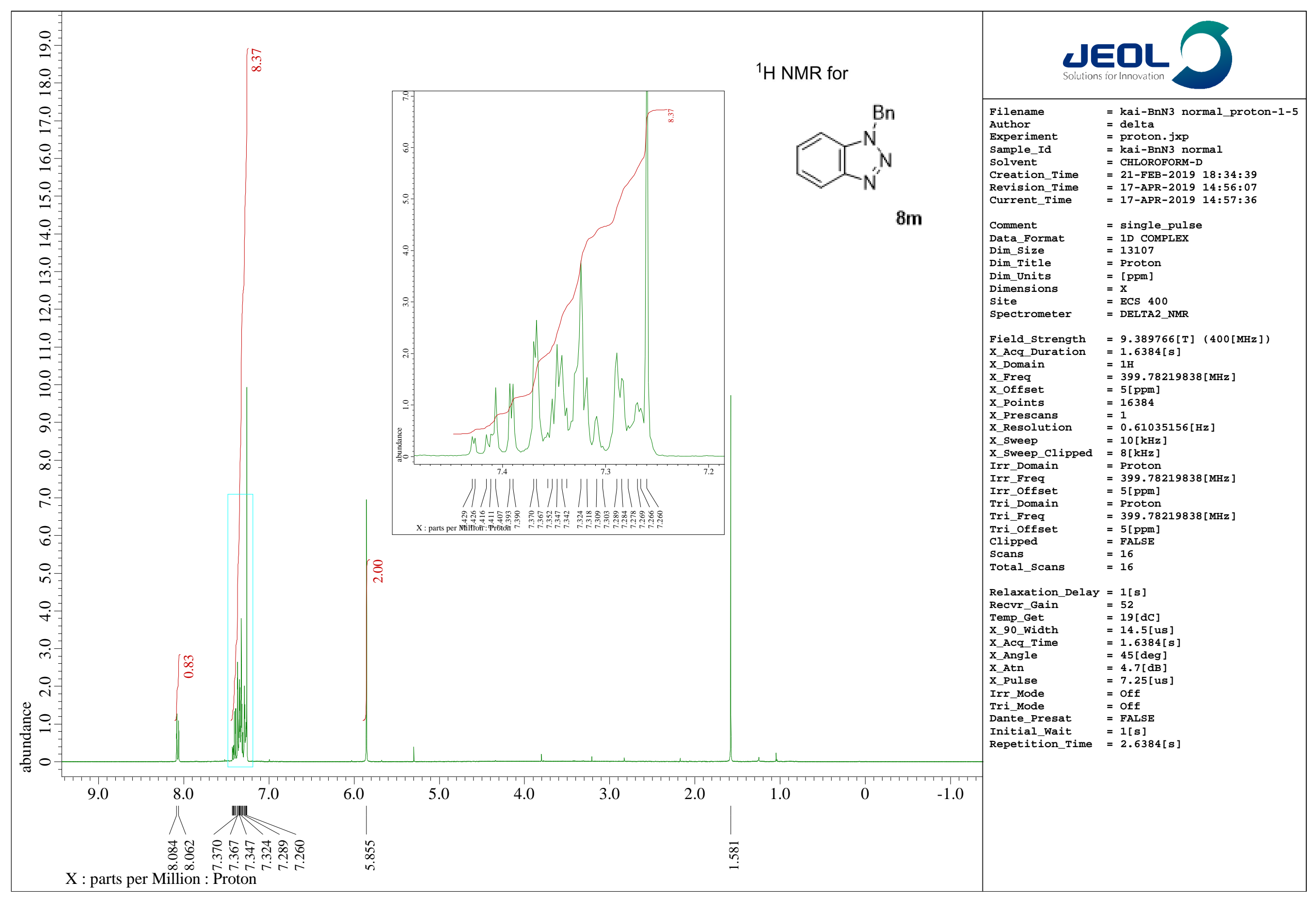




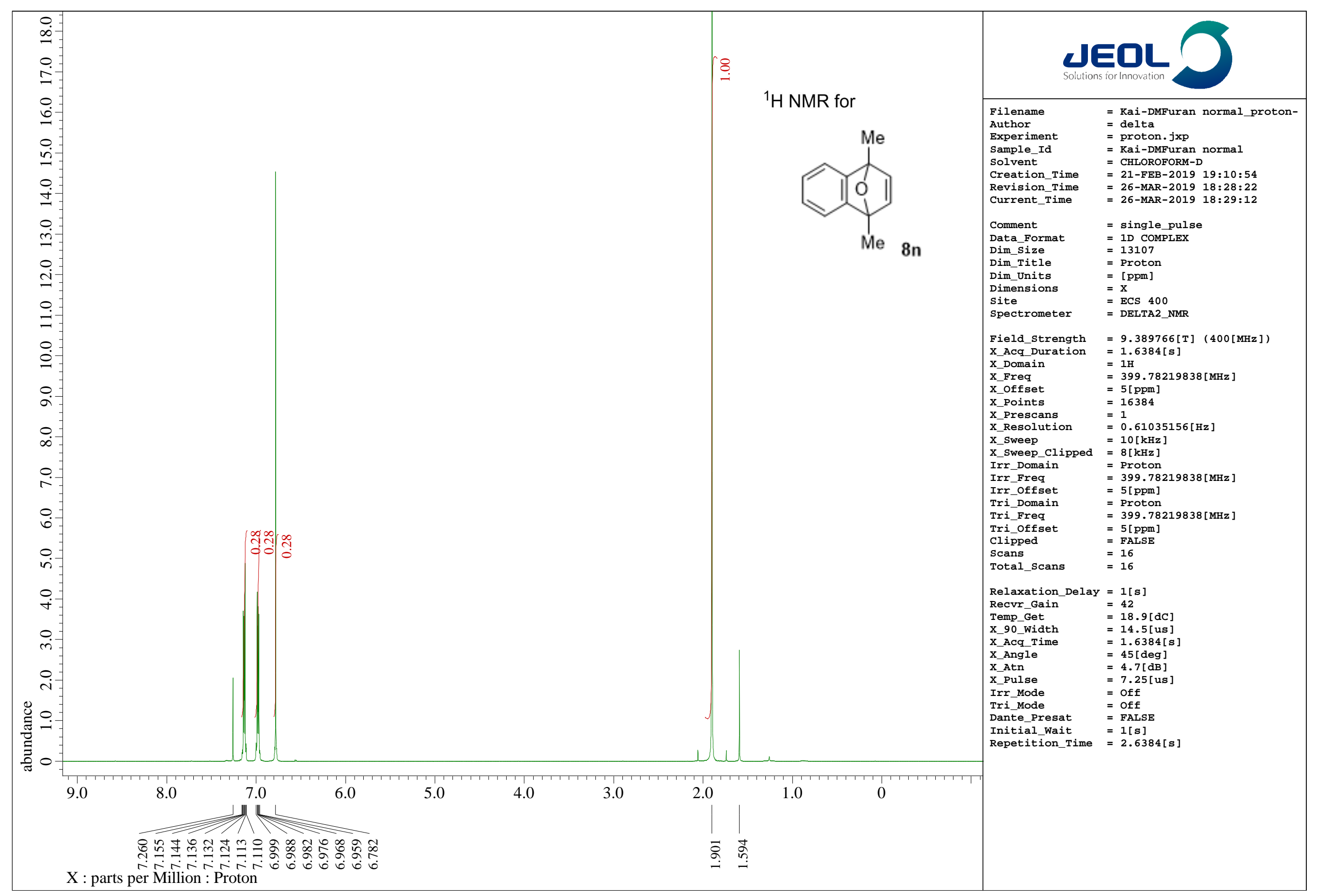




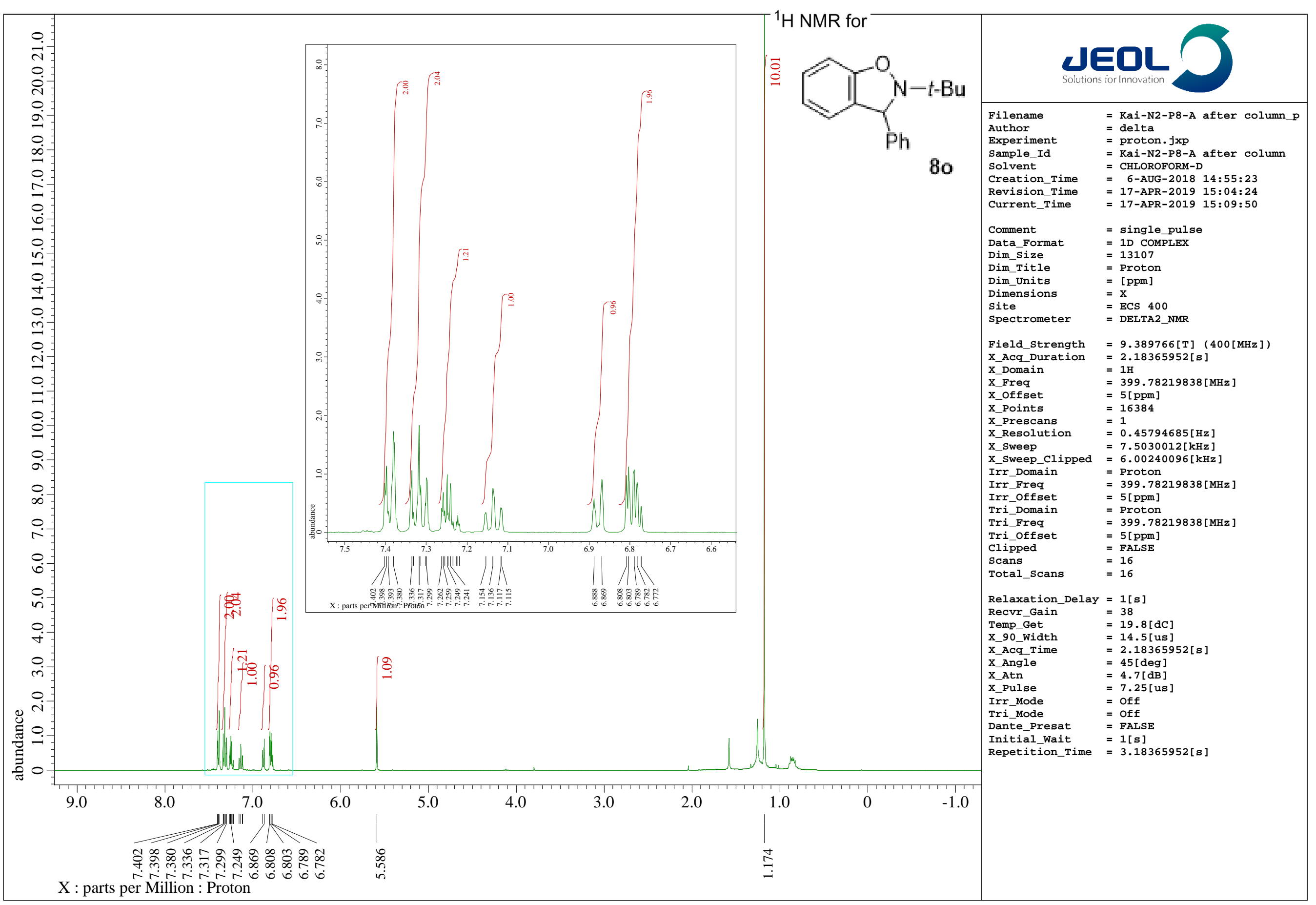




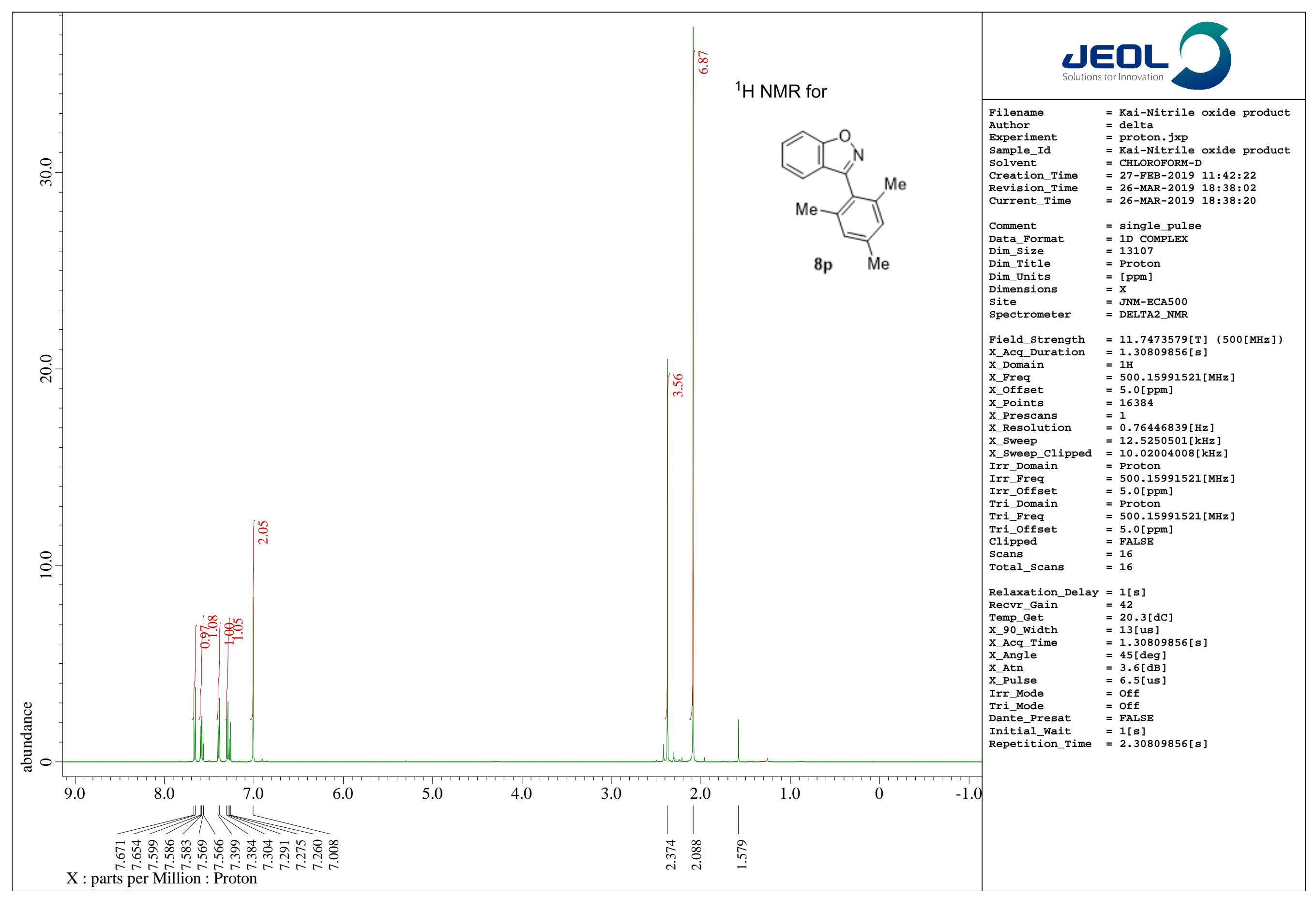




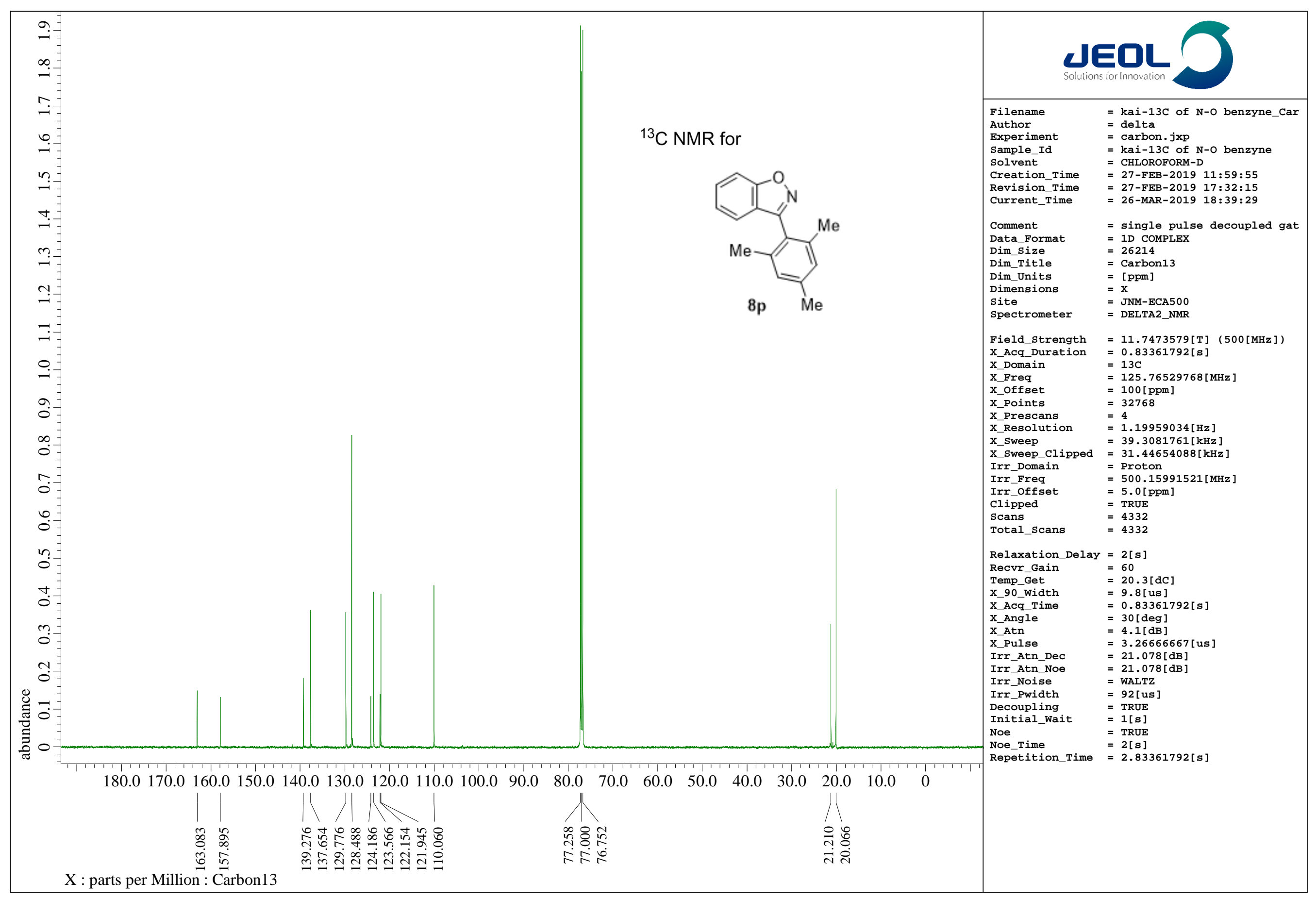




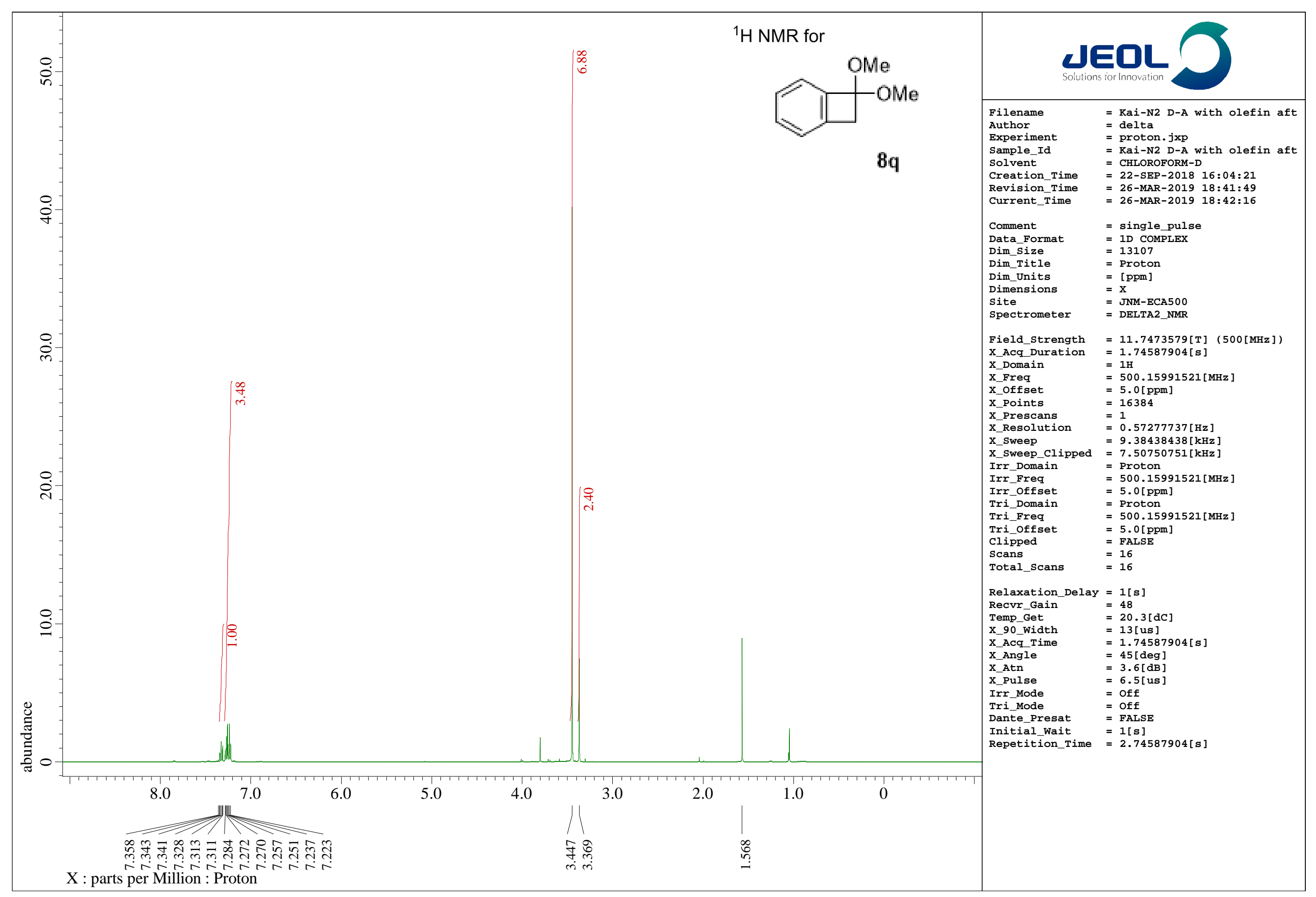




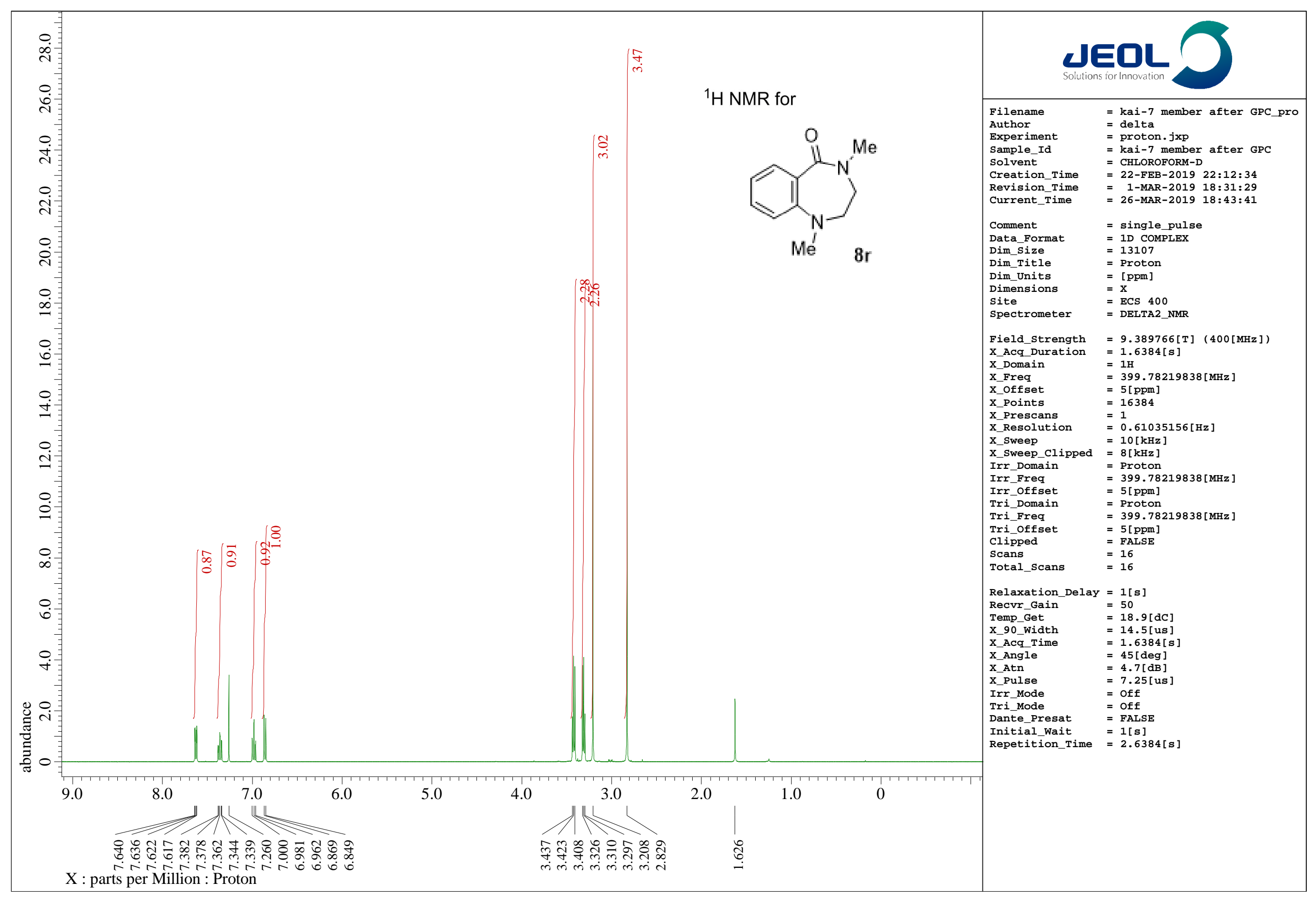




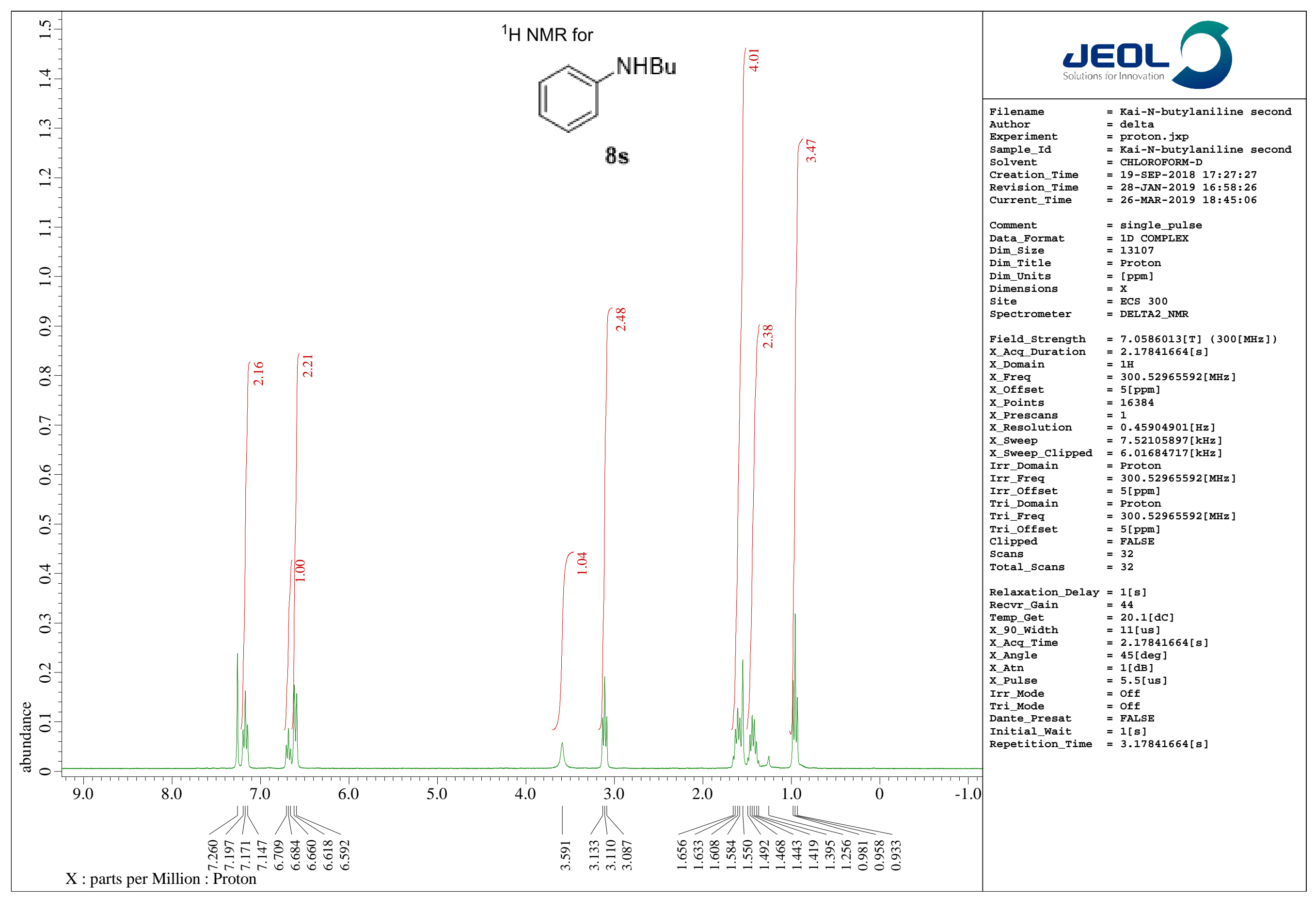




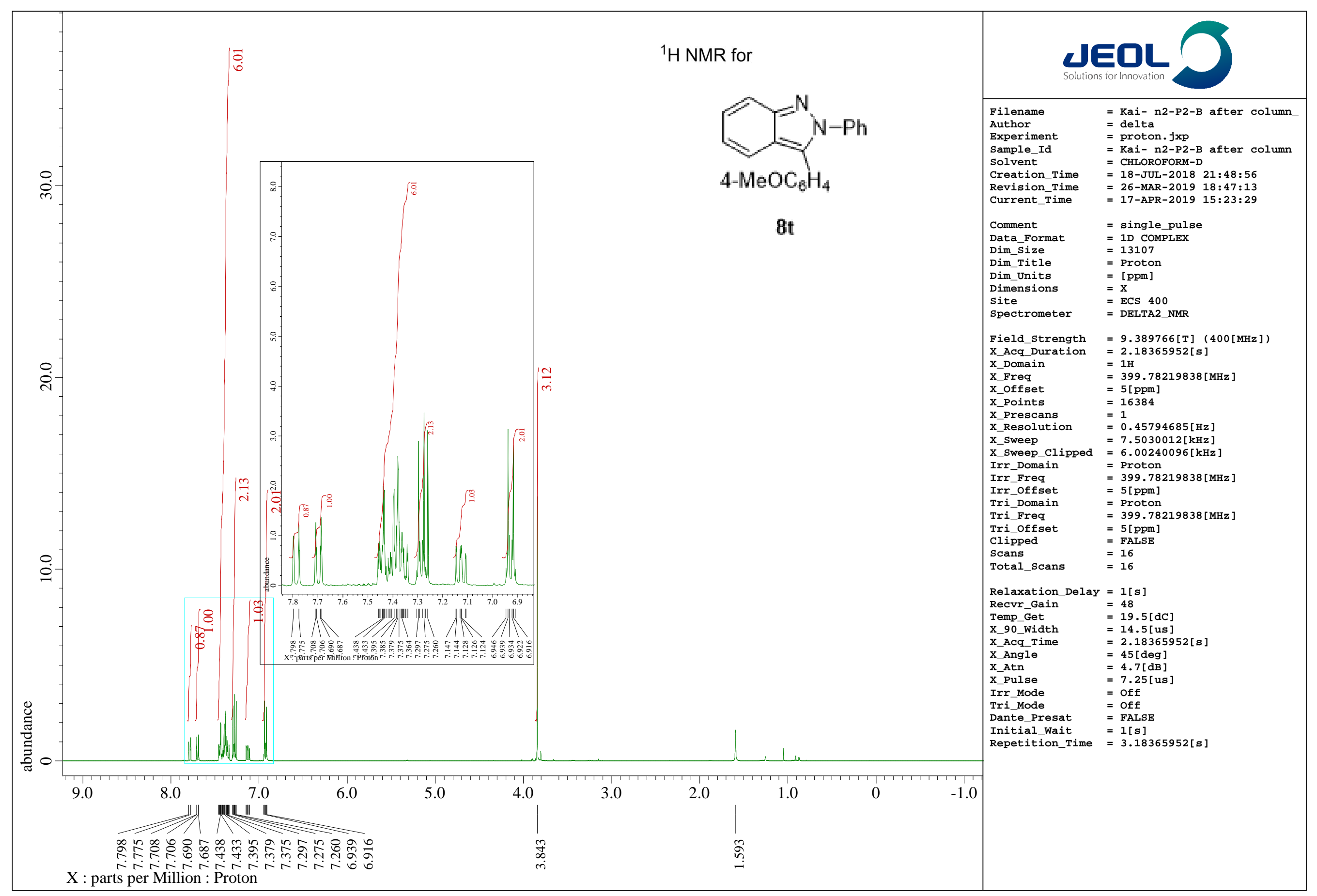




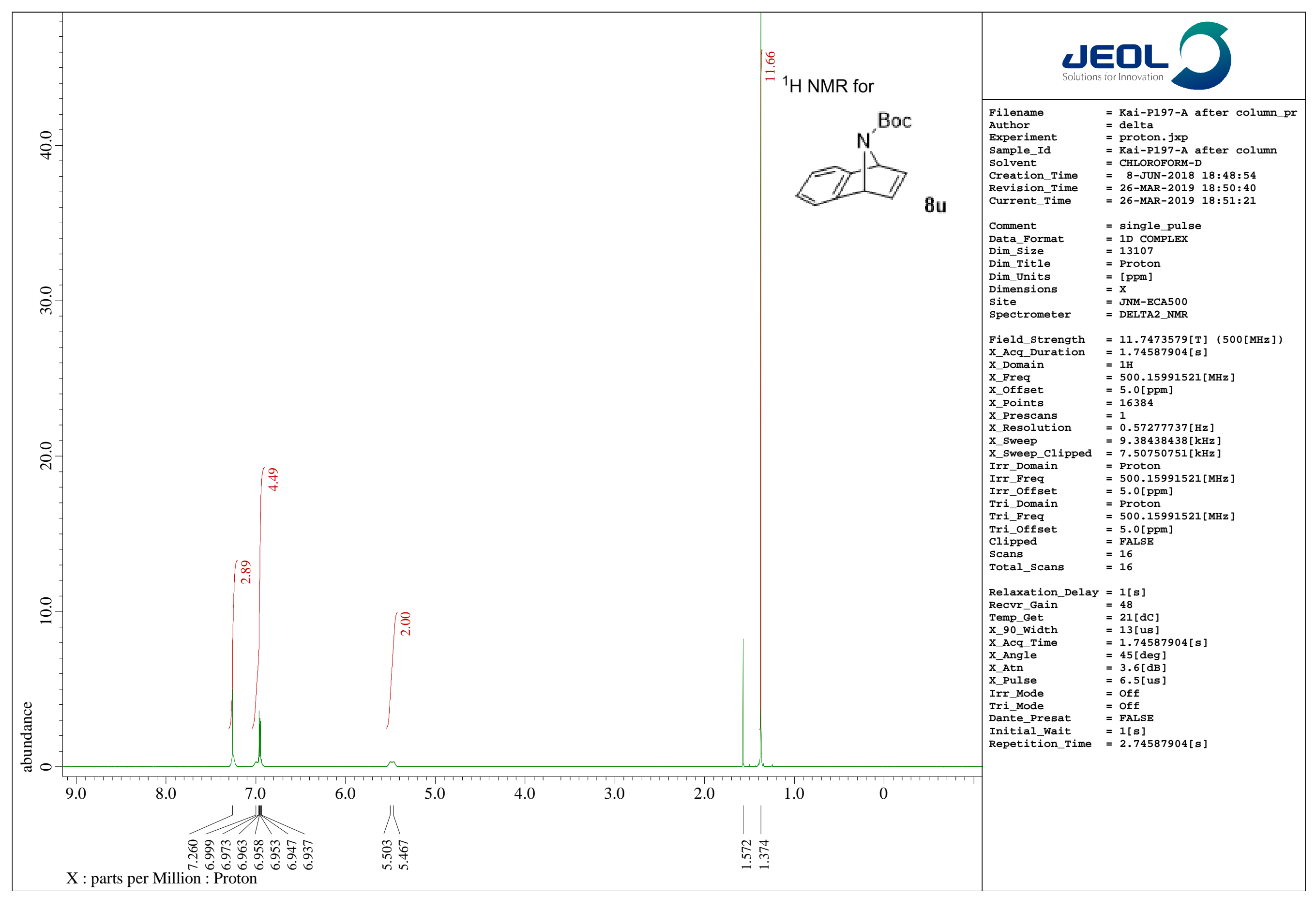




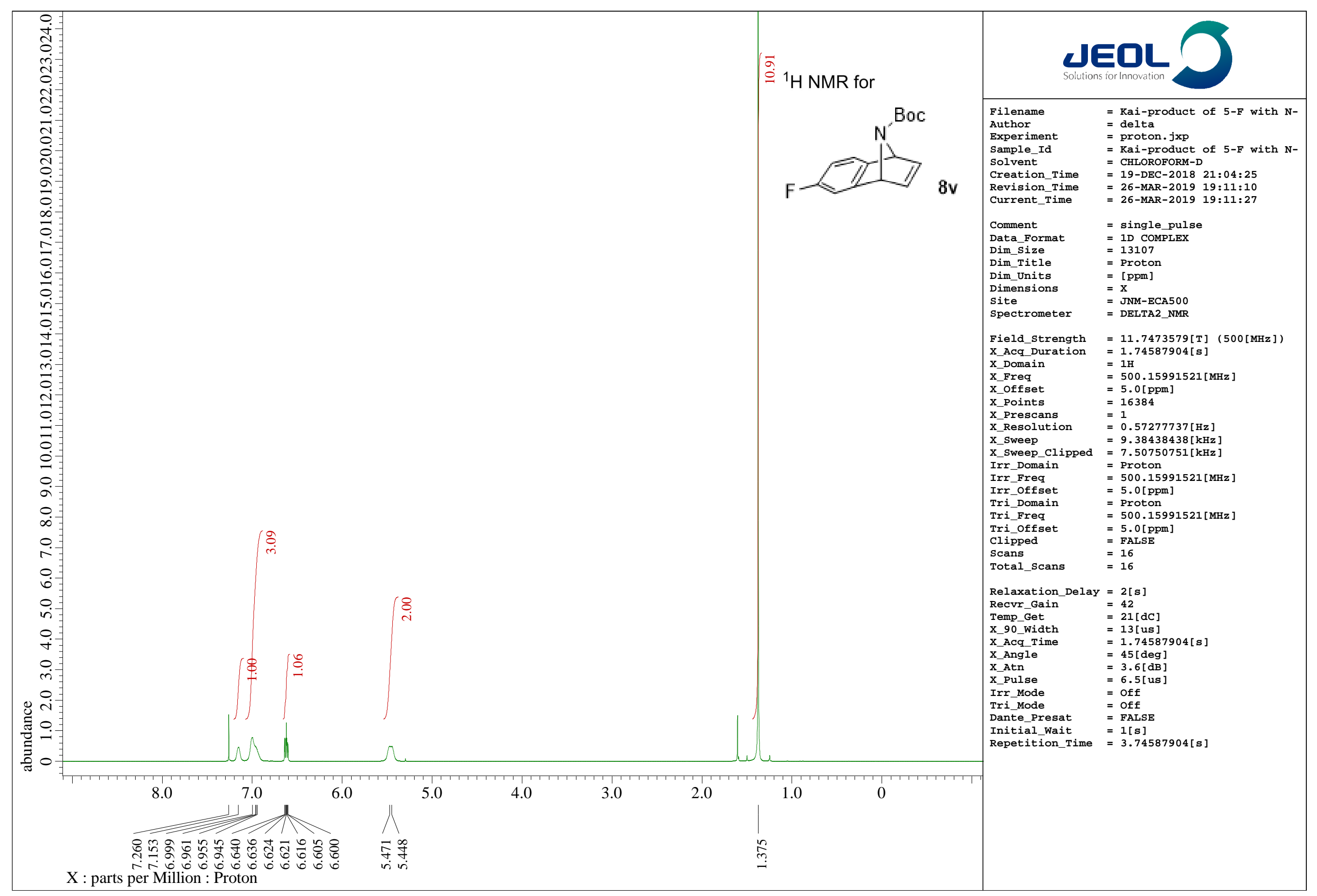




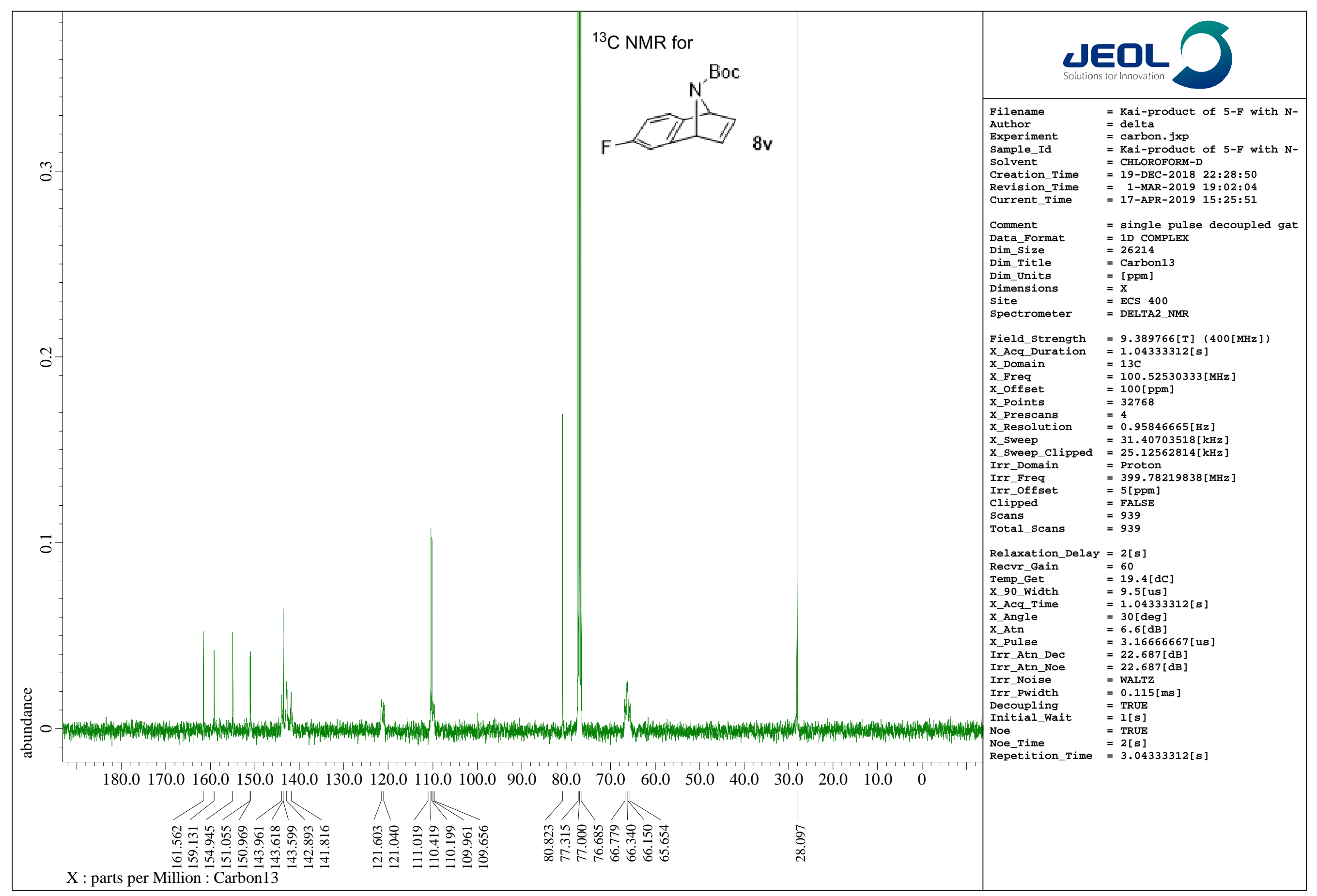




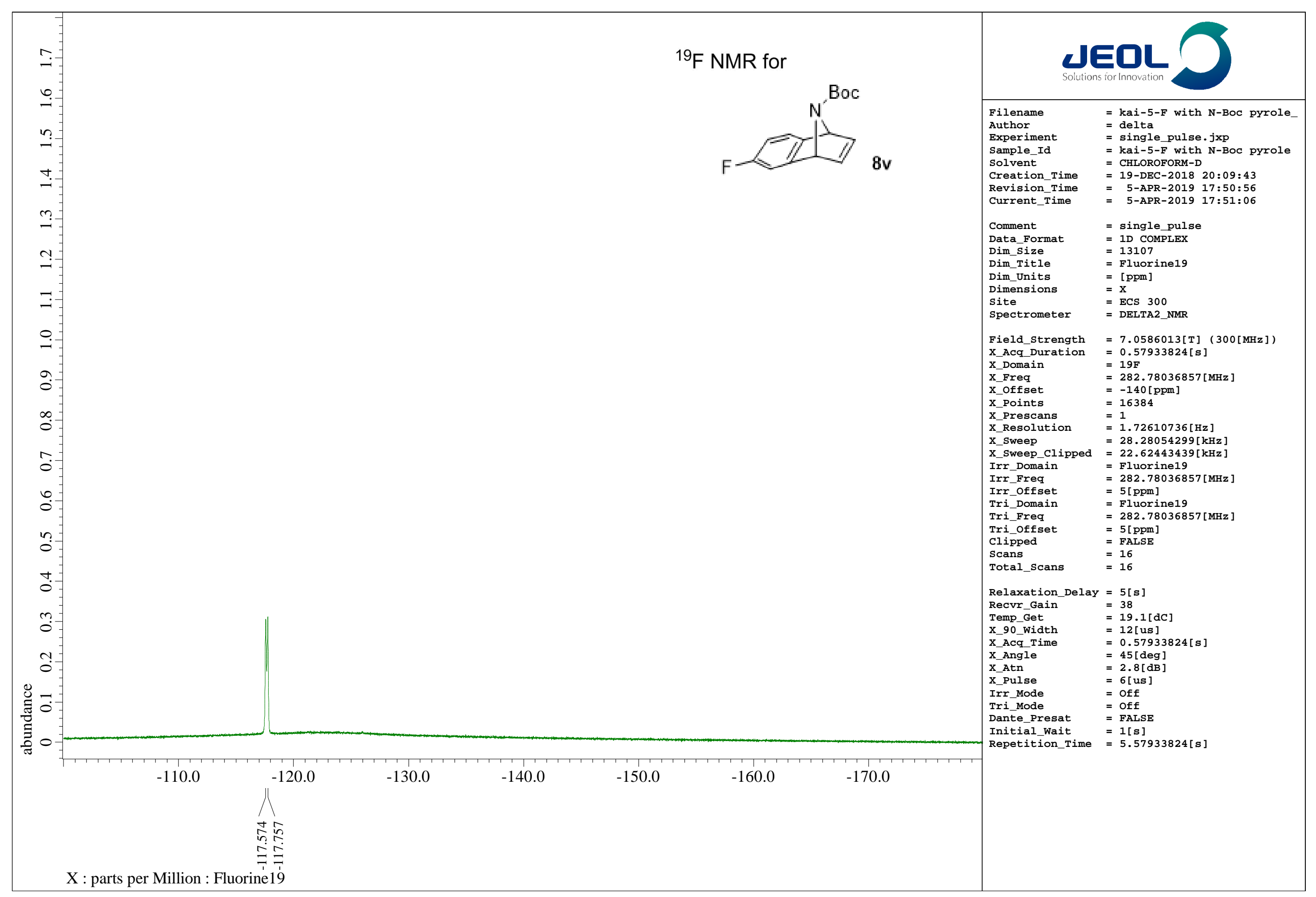




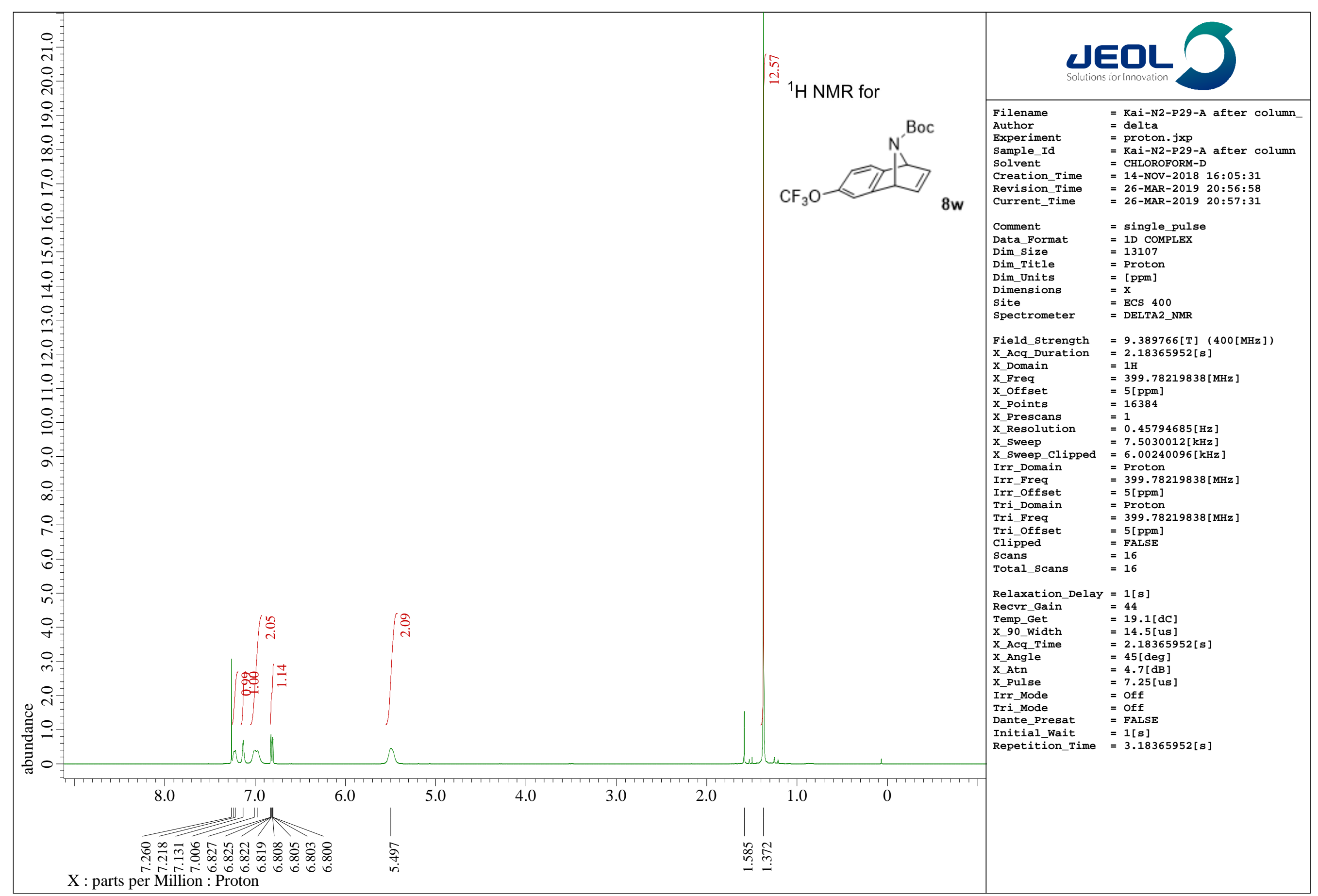




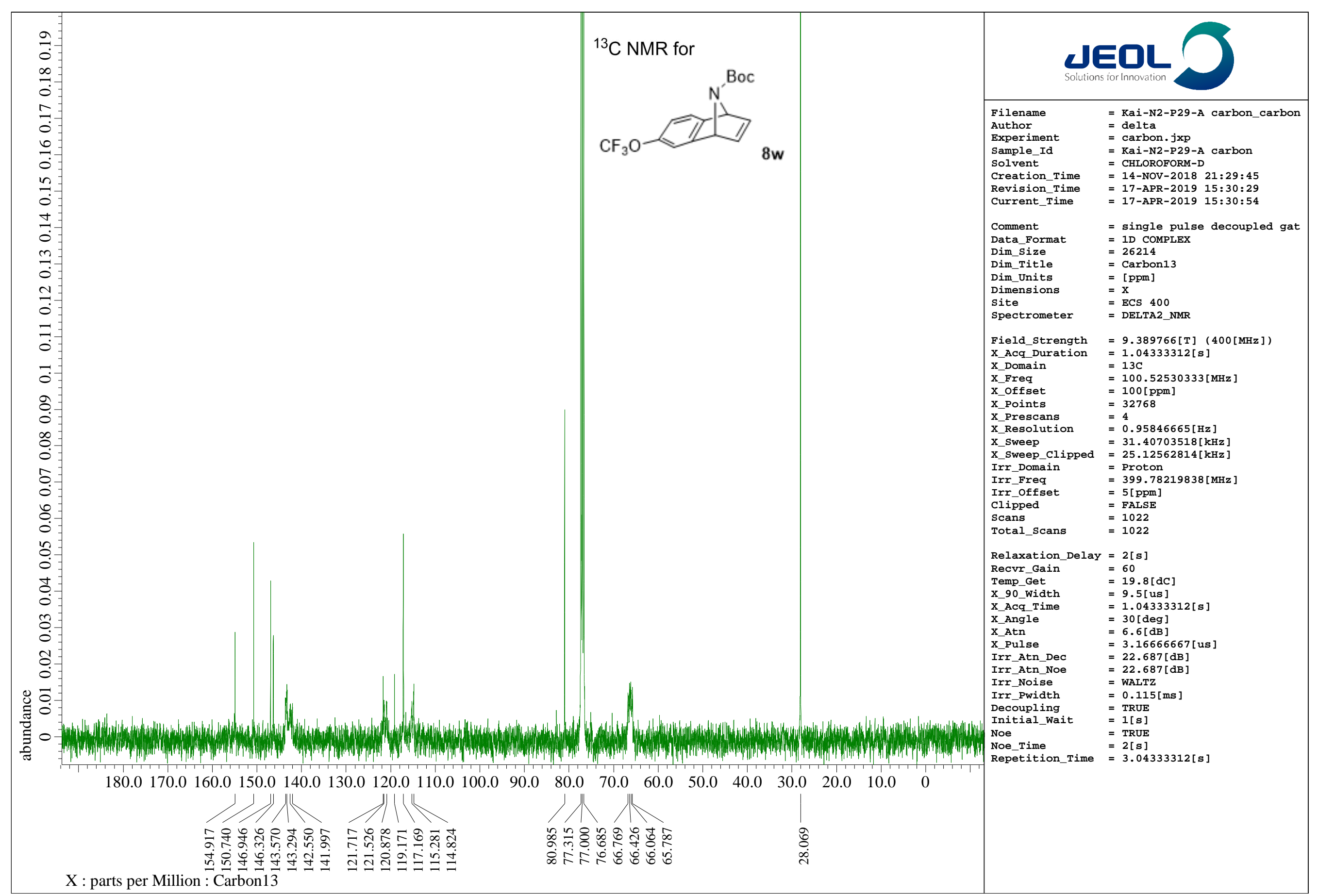


${ }^{19}$ F NMR for

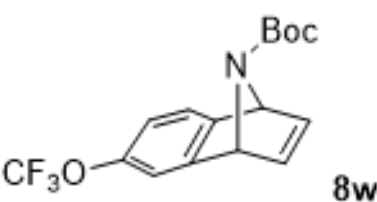

\section{JEOL}

Filename $\quad=$ Kai-N2-P29-A after column Author

$\begin{array}{ll}\text { Experiment } & =\text { single_pulse } \cdot \text { jxp } \\ \text { Sample_Id } & =\text { Kai-N2-P29-A after column }\end{array}$

Solvent

Creation_Time

Revision_Time

CHLOROFORM-D

14-NOV-2018 $16: 08: 49$

26-MAR-2019 $21: 10: 43$

Comment

$=$ single $\_$puls

Dim_size

$\begin{array}{ll}\text { Site } & =\mathrm{X} \\ \text { Site } 400\end{array}$

Spectrometer $=$ DELTA2

Field_Strength $=9.389766[\mathrm{~T}] \quad(400[\mathrm{MHz}])$

x_Acq_Duration $=1.38412032[\mathrm{~s}]$

x_Domain

$X_{-}$Freq

X_Offset

X_Points

X_Prescans

$=376.17105393[\mathrm{MHz}]$

$=131072$

$\begin{array}{ll}\text { X_Sweep } & =94.6969697[\mathrm{kHz}] \\ \text { X_Sweep_Clipped }^{2} & =75.75757576[\mathrm{kHz}]\end{array}$

Irr_Domain = Fluorine19

Irr_Freq $\quad=376.17105393[\mathrm{MHz}]$

Irr_offset

= Fluorine 19

Tri_Freq $\quad=376.17105393[\mathrm{MHz}]$

Clipped

Scans

Scans
Total_Scans

$=5[\mathrm{ppm}]$
$=$ FALSE

$=32$

Relaxation_Delay $=5[\mathrm{~s}]$

Recrr_Gain $=42$

$\begin{array}{ll}\text { Temp_Get } & =19.4[\mathrm{dC}] \\ \text { X_90_Width } & =15.6[\mathrm{us}]\end{array}$

X_Acq_Time $\quad=1.38412032[\mathrm{~s}]$

$x_{-A n g l e} \quad=45[\mathrm{deg}]$

$\begin{array}{ll}X_{\text {_Atn }} & =4.5[\mathrm{~dB}] \\ \mathrm{X}_{\text {_Pulse }} & =7.8[\mathrm{us}]\end{array}$

$\begin{array}{ll}\text { X_Pulse } & =7.8[\mathrm{us} \\ \text { Irr_Mode } & =\text { Off }\end{array}$

$\begin{array}{ll}\text { Irr_Mode } & =\text { Off } \\ \text { Tri_Mode } & =\text { Off }\end{array}$

Dante_Presat

$\begin{array}{ll}\text { Initial_Wait } & =1[\mathrm{~s}] \\ \text { Repetition_Time } & =6.38412032[\mathrm{~s}]\end{array}$

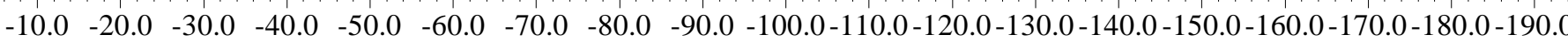




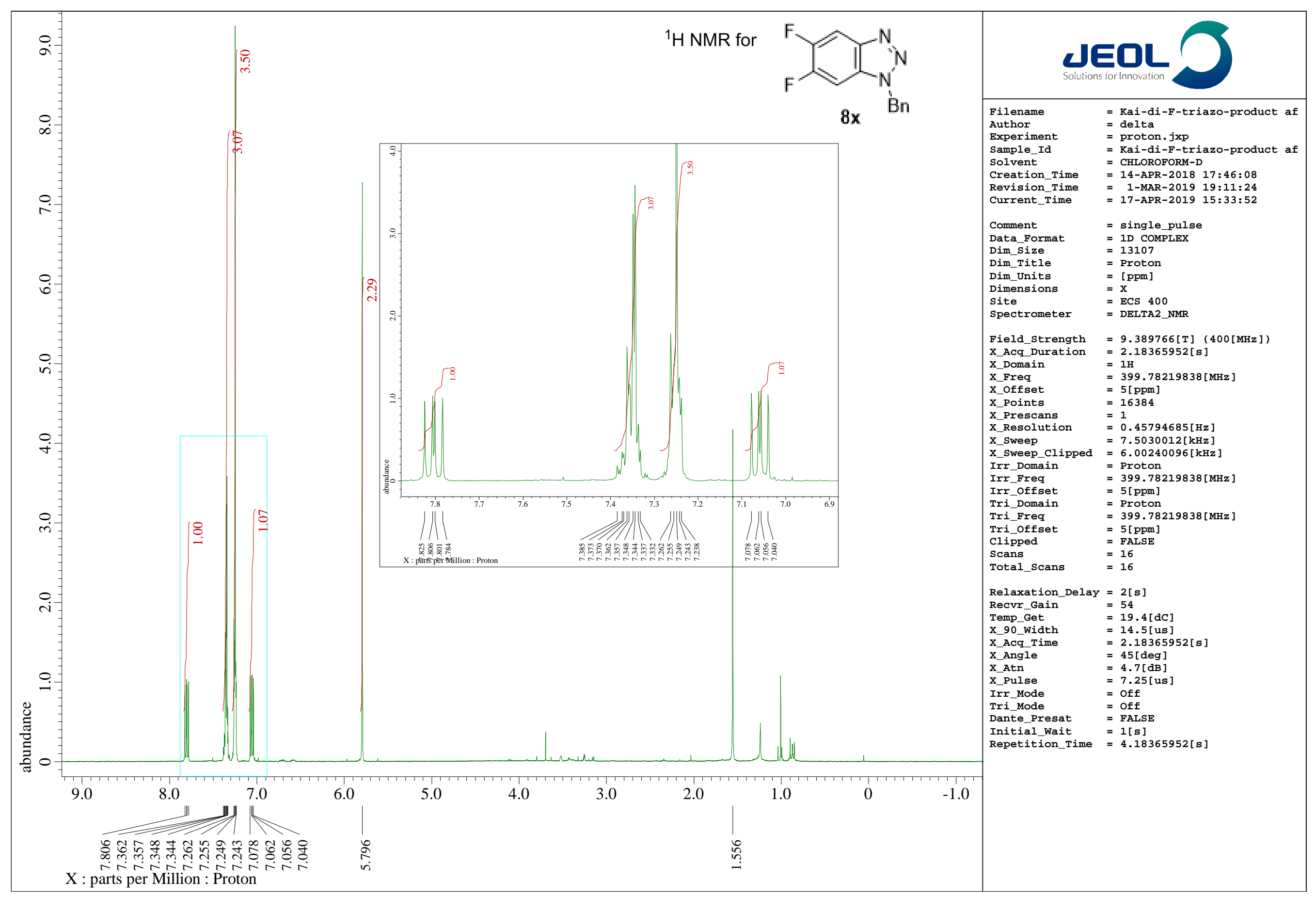




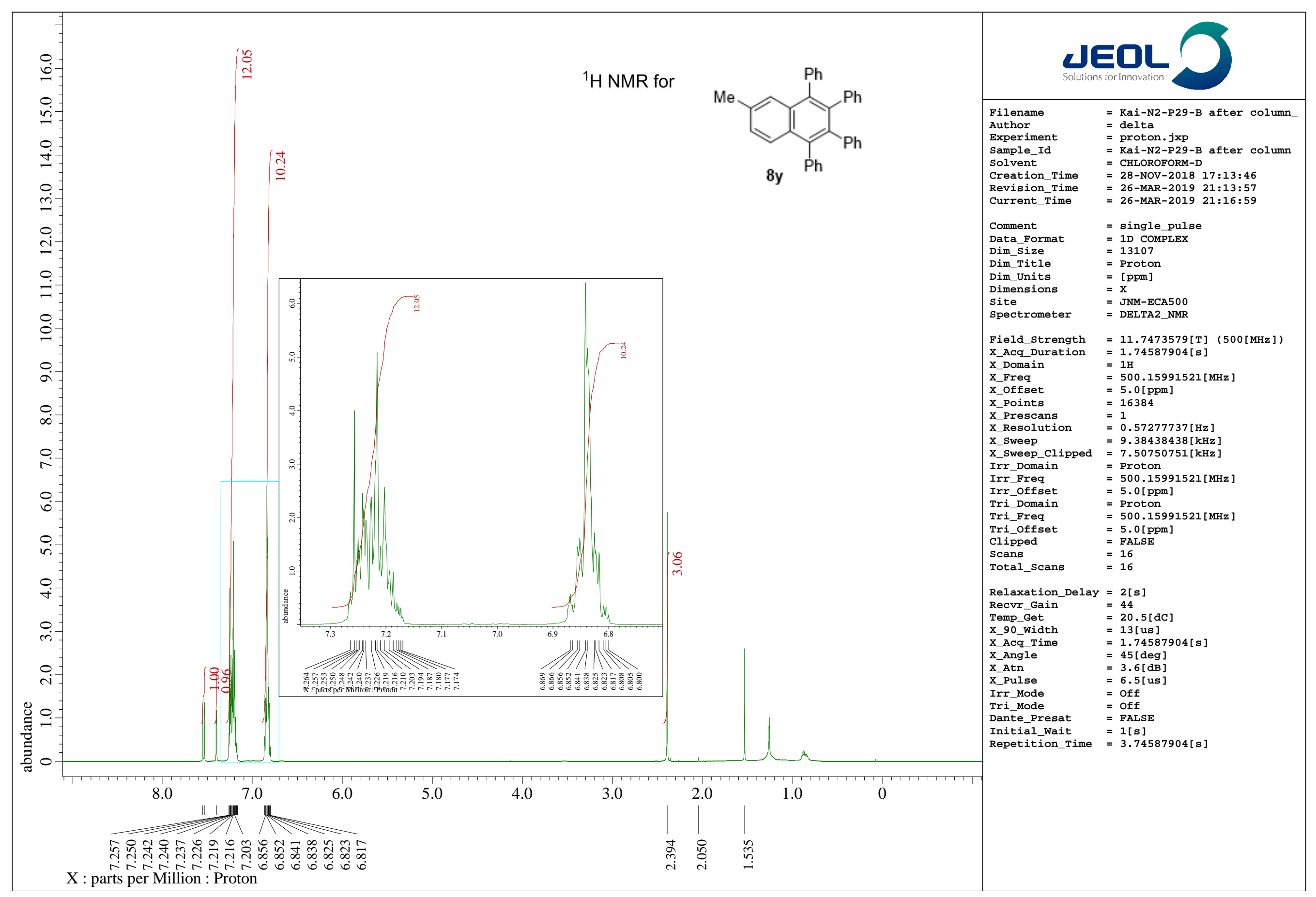

